\title{
SYNTHESIS AND CHARACTERIZATION OF LINEAR AND BRANCHED POLYLACTIC ACID FOR USE IN FOOD PACKAGING APPLICATIONS
}

\author{
A Project Report presented to the Faculty of \\ California Polytechnic State University, San Luis Obispo
}

In Partial Fulfillment of

The Requirements for the Degree of Master of Science in Polymers and Coatings Science

\author{
By \\ Kyle Clinton Bentz
}

June 2011 
(C)2011

Kyle Clinton Bentz

ALL RIGHTS RESERVED 


\section{COMMITTEE MEMBERSHIP}

TITLE:

AUTHOR:

DATE SUBMITTED:

COMMITEE CHAIR:

COMMITTEE MEMBER:

COMMITTEE MEMBER:
SYNTHESIS AND CHARACTERIZATION OF LINEAR AND BRANCHED POLYLACTIC ACID FOR USE IN FOOD PACKAGING APPLICATIONS

KYLE C BENTZ

JUNE 17, 2011

Chad E. Immoos, Associate Professor

Raymond H. Fernando, Professor 


\begin{abstract}
Synthesis and Characterization of Linear and Branched Polylactic Acid for Use in Food Packaging Applications

Kyle Clinton Bentz

Polylactic acid (PLA) resins of various molecular weights and molecular weight distributions were synthesized. Linear, narrow molecular weight distribution (MWD) PLA resins were synthesized, as well as resins containing both high molecular weight branched structures and low molecular weight chains and oligomers. Narrow MWD resins were synthesized for use as adhesives for corrugated paperboard and broad MWD resins were synthesized for use as a waterborne coating. PLA resins were dispersed for use as a waterborne coating. Success has been made at forming films utilizing various plasticizers and surfactants as well as polyvinyl alcohol as dispersing agents. A cold dispersion procedure realized the most success, as a 15\% PLA waterborne formulation was achieved. Standard test methods show a high degree of grease resistance for the formulated coatings. A hot melt adhesive was also formulated utilizing blends of narrow MWD resins of various molecular weights. The hot melt adhesive showed a high degree of success as failure occurred at the substrate for the materials tested.
\end{abstract}




\section{TABLE OF CONTENTS}

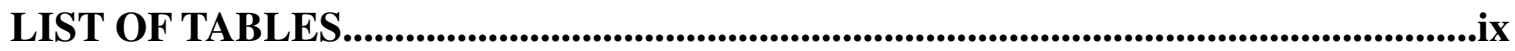

LIST OF FIGURES................................................................................................................xi

LIST OF SCHEMES..................................................................................................

1. Literature Review..................................................................................................................1

1.1 A Brief History of Polymers.............................................

1.2 History of Biodegradable Polymers...................................

1.2.1 Definition of a Biodegradable Polymer.............................3

1.2.2 Types of Biodegradable Polymers................................ 3

$1.3 \quad$ Polylactic Acid..................................................... 4

1.3.1 PLA Market.......................................................

1.3.2 Lactic Acid and Lactide Monomer..................................5

1.3.3 Polymerization and Synthetic Methods............................6

1.3.3.1 Condensation of Lactic Acid................................6

1.3.3.2 Solid State Polymerization................................ 8

1.3.3.3 Ring Opening Polymerization..........................9

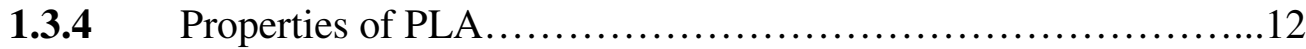

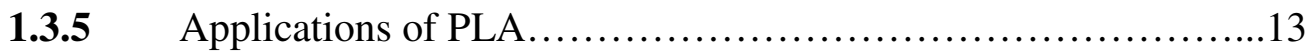

1.3.5.1 Packaging Applications.................................14

1.3.5.2 Hot Melt Adhesive.....................................15

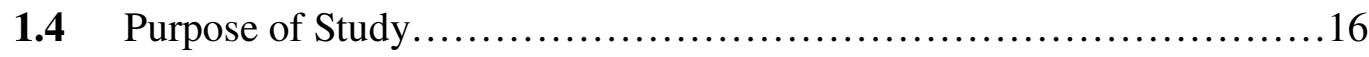


1.4.1 Waterborne Coating..................................... 16

1.4.2 Hot Melt Adhesive.........................................17

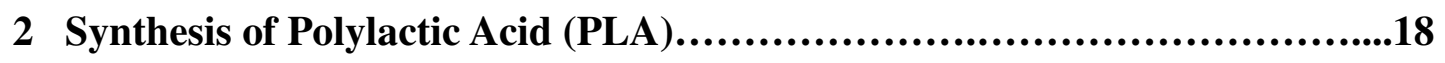

2.1 Synthesis Methods............................................18

2.1.1 Bulk Polymerization......................................18

2.1.2 Solution Polymerization.....................................19

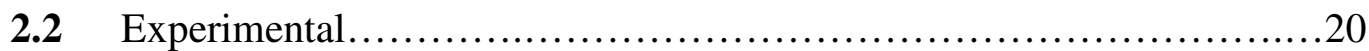

2.2.1 Materials.................................................20

2.2.2 Polymerization of Lactide in Bulk...........................20

2.2.3 Polymerization of Lactide in Solution...........................21

2.3 Results and Discussion..........................................22

2.3.1 Bulk Polymerization.......................................22

2.3.2 Solution Polymerization................................... 30

2.4 Conclusions.......................................................... 31

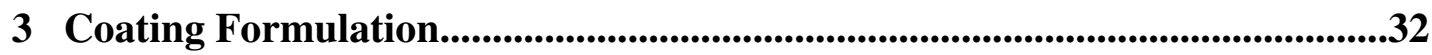

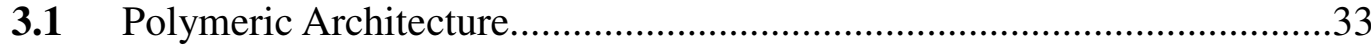

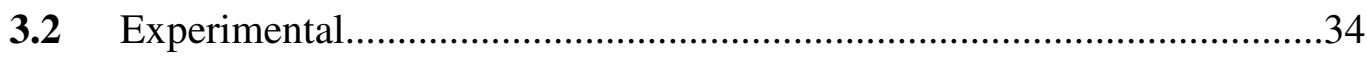

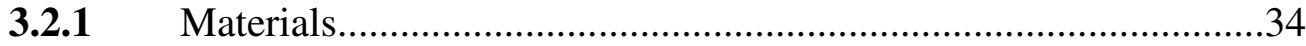

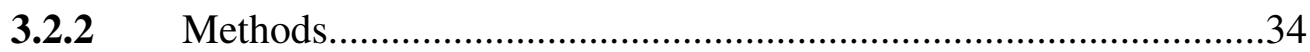

3.2.2.1 Hot Dispersion......................................35

3.2.2.1.1 General Procedure for Hot Dispersion......................36

3.2.2.1.2 Hot Dispersion Procedure, Samples PLA 13-PLA18.........36 
3.2.2.2 Solvent Switch Procedure, Samples PLA 14, 16, and 18...37

3.2.2.3 Second Hot Dispersion Procedure, Samples PLA 19-29....37

3.2.2.4 Third Hot Dispersion Procedure, Samples PVA 1 - PVA

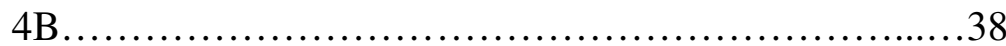

3.2.2.5 Fourth Hot Dispersion Procedure, Samples PVA 4C33 -

PVA 7A35........................................ 38

3.2.2.6 Cold Dispersion Procedure, Samples PVA 8A36 - PVA

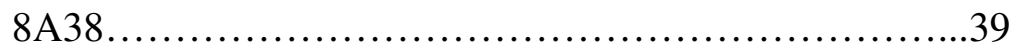

3.3 Results and Discussion............................................40

3.3.1 Hot Dispersion, Samples PLA 13 - PLA 18.............................40

3.3.2 Solvent Switch, Samples PLA 14, 16, and 18............................41

3.3.3 Second Hot Dispersion, Samples PLA 19-29..........................42

3.3.3.1 Choice of Plasticizer...................................43

3.3.3.2 Choice of Surfactant.......................................................44

3.3.4 Third Hot Dispersion, Samples PVA 1 - PVA 4B.........................44

3.3.5 Fourth Hot Dispersion, Samples PVA 4C33 - PVA 7A35............48

3.3.6 Cold Dispersion, Samples PVA 8A36 - PVA 8A38.....................49

3.3.7 Attempts at Scale Up of PVA 8A37.........................................53

3.4 Coating Application and Testing.....................................................53

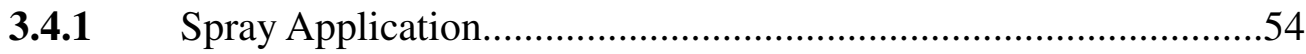

3.4.1.1 Spray Procedure..........................................................54

3.4.1.2 Coating Testing Procedure............................................55 
3.4.2 Results and Discussion..........................................................56

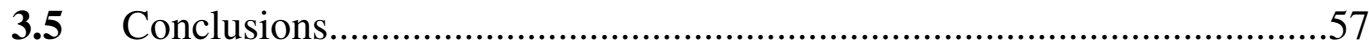

4 Hot Melt Adhesive.................................................................59

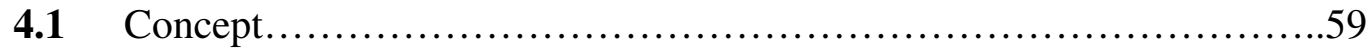

4.2 Experimental..............................................60

4.2.1 Materials.................................................60

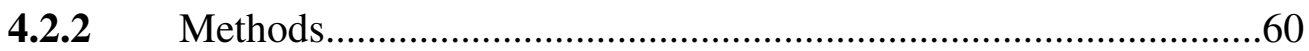

4.2.2.1 Differential Scanning Calorimetry (DSC) Method.........60

4.2.2.2 Thermal Gravimetric Analysis (TGA) Method.............60

4.2.2.3 Hot Melt Adhesive Preparation Procedure........................61

4.3 Results and Discussion...........................................61

4.3.1 Results of Peel Test..........................................................61

4.3.2 Use of Plasticizer..........................................61

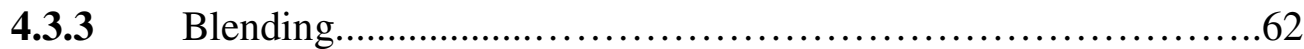

4.3.4 Thermal Properties......................................62

4.3.5 Thermal Stability.............................................64

4.3.6 Temporal Stability........................................64

4.3.6.1 Thermal Stability..................................64

4.3.6.2 Molecular Weight Degradation................................66

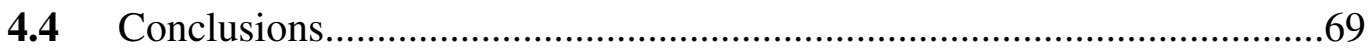

5 Conclusions............................................................70

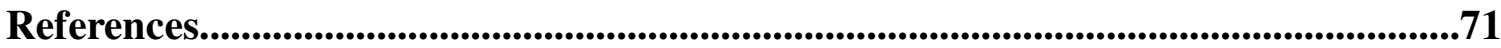




\section{LIST OF TABLES}

Table

Page

1.1 Mechanical Properties of PLA, compared with polystyrene and polyethylene 13 terephthalate

2.1 Summary of the polymerization conditions for polymers synthesized in bulk 21

2.2 Summary of the polymerization conditions for polymers synthesized in 22 solution

2.3 Summary of the final molecular weights obtained for the polymers synthesized in bulk

2.4 Summary of changes in molecular weight and molecular weight distribution 25 for various PLA samples

2.5 Summary of the molecular weights and MWD of the polymers synthesized for use as a hot melt adhesive

3.1 Summary of the first attempts at hot dispersion, samples PLA 13 - PLA $18 \quad 40$

3.2 Summary of the attempts at the solvent switch method, samples PLA 14, 16, 42 18

3.3 Summary of the various experiments for the second hot dispersion technique 43

3.4 Summary of experiments performed in third hot dispersion procedure 48

3.5 Summary of weight percent solvent (acetone) added to samples PVA $2-4 B \quad 48$

3.6 Summary of the ingredients in samples PVA 4C33 - PVA 7A35 49

3.7 Summary of Samples PVA 8A36 - PVA 8A38 50

3.8 Summary of the polymers used in samples PVA 8A36, PVA 8A37, and 51 PVA 8A38

3.9 Final formulation of polylactic acid waterborne coating 53

3.10 Summary of average coat weight for spray applied coatings 55

3.11 Results of grease resistance testing 56 
4.1 Summary of the glass transition temperatures $(\mathrm{Tg})$ for the polymers synthesized

4.2 Thermal stability of polymers synthesized for use as a hot melt adhesive

4.3 Summary of the molecular weights and molecular weight distributions of the polymer samples PLA 1, 11, and 12 over time 


\section{LIST OF FIGURES}

Figure $\quad$ Page

$1.1 \quad$ Structure of stannous octoate $\quad 11$

2.1 GPC analysis of PLA 14 and PLA 15

2.2 GPC analysis of PLA 16 27

2.3 GPC analysis of PLA 23 and PLA 24

$2.4 \quad$ GPC analysis of PLA $27 \quad 29$

3.1 Schematic view of a PLA particle interacting with surfactant chains 32

3.2 Structure of Hexamoll 44

3.3 Structure of Triton X-200 44

3.4 Strutures of polyvinyl acetate, polyvinyl alcohol, and polylactic acid 46

3.5 Schematic of the method of action for dispersing aid, polyvinyl alcohol 46

3.6 Schematic of dispersion of PLA particles 50

3.7 GPC analysis of polymers PLA 36, 37 and 38

3.8 Schematic illustrating the benefits of spray application of coatings 54

3.9 Grease resistance testing for uncoated and coated samples in accordance 57 with ASTM D722

4.1 Graph of Tg versus molecular weight. $\left(\mathrm{R}^{2}=0.77\right)$

4.2 Thermal stability for PLA 1

4.3 GPC analysis of PLA 1 over time $\quad 67$

4.4 GPC analysis of PLA 11 over time $\quad 68$

4.5 GPC analysis of PLA 12 over time 68 


\section{LIST OF SCHEMES}

Scheme

Page

1.1 Condensation polymerization mechanism 8

1.2 Solid state polymerization of PLA 9

1.3 Anion polymerization mechanism 9

$\begin{array}{lll}1.4 & \text { Cation polymerization mechanism } & 10\end{array}$

1.5 Coordination-insertion mechanism for polymerization of lactide 12

3.1 Synthetic route for the preparation of linear and branched polylactic 34 acid polymers 


\section{Literature Review}

\subsection{A Brief History of Polymers}

As mankind has progressed throughout history he has established an increasingly advanced use of tools and the materials from which they are made. Man began to make tools from stone, then progressed to copper, bronze, and eventually iron. With a greater understanding of various metals, stronger and more useful alloys were developed,

providing mankind with more opportunities to invent and innovate. In the early $20^{\text {th }}$ century another paradigm shift was seen in material usage with the invention of polymeric materials. As scientists were better able to manipulate chemical processes, advanced materials could finally be built atom by atom. Man had always used materials provided by nature, but was now, for the first time in human history, able to build fully synthetic materials from basic molecular starting materials.

Polymer science, in a broad sense, began in the 1800's with work done by Henri Braconnot and Christian Schönbein on derivatives of the natural polymer cellulose such as celluloid, and cellulose acetate, which are still commonly used today. ${ }^{1}$ Jons Jacob Berzelius can be credited with coining the term 'polymer' into the scientific lexicon. It was Berzelius who proposed the idea that two compounds could have the same composition but different molecular weights, a key concept in polymer science. Hermann Staudinger would later expand on this concept with the theory of long molecular chains with weights in the hundreds of thousands held together by normal covalent bonds. Staudinger would later coin the term 'macromolecule' and would go on to win the Nobel Prize in Chemistry in 1953 for his work on the subject. ${ }^{2}$ 
The first truly synthetic polymer developed was called Bakelite, in 1907, by Leo Baekeland. ${ }^{3}$ Polystyrene was invented in 1930, and has become one of the most widely used polymers today, especially in packaging. In 1938, Nylon was invented by Wallace Carothers of DuPont, and is still in wide use today. Polyethylene was invented in 1941, and the synthetic procedures involved in creating its various forms (low density, high density, linear low density) would be developed in large part by Karl Ziegler and Giulio Natta, who would win the Nobel Prize in Chemistry in 1963 for their work in this field. ${ }^{3}$ Funding for the research and development of polymers, and chemistry in general, increased dramatically during World War II and the following decades would see an increase in development of high performance polymers, an example being Kevlar in 1971. Polymers would become the nation's most widely used material per unit volume in 1976, and today the nation uses more plastics than all metals combined. ${ }^{3}$

\subsection{History of Biodegradable Polymers}

As synthetic polymers have become an increasingly prominent, even integral, part of daily life the question of how to properly dispose of and manage all the plastic waste is becoming a serious one, and is seeing a large amount of research being put into solving it. While recycling current materials is a viable option, and is certainly for the time being a necessary option, many efforts are focused on creating sustainable, biodegradable plastics. The last two decades have seen a marked increase and interest in biopolymer research. As society begins to understand the effect our lifestyles and technological advances have had on our environment and planet, the demand for biodegradable and sustainable materials is on the rise. The term 'sustainability' was first coined by the 
Brundtland Commission and is defined as, "social and economic advance to assure human beings a healthy and productive life, but one that did not compromise the ability of future generations to meet their own needs. ${ }^{, 4}$ Now that plastics have been part of our lifestyles for multiple decades, the life cycles of these materials and their products are becoming a matter of intense study.

\subsubsection{Definition of a Biodegradable Polymer}

A biodegradable polymer is defined, in the context of this paper, as being hydrolyzable at temperatures up to $50{ }^{\circ} \mathrm{C} .{ }^{5}$ In addition, it is important for the degradation products of the polymer to be non-toxic. Ideally, a biodegradable polymer will be derived from renewable sources and fit the aforementioned description of 'sustainability.'

\subsubsection{Types of Biodegradable Polymers}

There are many types of biodegradable polymers which fall into two main categories. There are the biodegradable polymers which are naturally produced or based primarily on renewable sources (commonly starch). ${ }^{6}$ These include polysaccharides (starch, cellulose, etc.), proteins (gelatine, wool, silk, etc.), lipid fats (fats and oil), polyesters produced by plants or microorganisms (polyhydroxyalkanoates PHAs), polyesters derived from bioderived monomers (polylactic acid), and several miscellaneous polymers like natural rubbers and composites. The other type are nonrenewable, synthetic, biodegradable plastics which are petroleum based such as polybutylene succinate (PBS) and polycaprolactone (PCL). Other polymers which are biodegradable but do not fit neatly into either category are polyanhydrides and polyvinyl alcohol. 
Perhaps the most widely studied biodegradable polymers, which show the most promise as a replacement for petroleum based thermoplastics, are polyesters. Depending on the structure of the polyesters, the ester bond may be hydrolyzable under certain conditions, thus making it biodegradable. There are two major groups of of polyesters, aliphatic (linear) polyesters and aromatic (aromatic rings) polyesters. Typically, the aliphatic polyesters show improved biodegradability over their aromatic counterparts due to the stability of the aromatic ring. However, aliphatic-aromatic copolymers can be shown to be fully biodegradable. ${ }^{7}$ Specifically the polyester and copolyesters of several $\alpha-, \beta-$, and $\omega$-hydroxy acids have been used widely during the past 20 years. ${ }^{5}$

\subsection{Polylactic Acid (PLA)}

\subsubsection{PLA Market}

Bioplastics constitute nearly 300,000 metric tons of the global plastics market. ${ }^{6}$ Although this is a large number, and alone would constitute a significant industry, it pales in comparison to the 181 million metric tons of total plastics produced globally each year, of which nearly $40 \%$ are used for packaging. ${ }^{8}$ In 2003 , the sales of polymeric biomaterials exceeded $\$ 7$ billion, accounting for almost $88 \%$ of the total biomaterial market for that year. ${ }^{9}$ The bioplastic industry is growing, however, at a rate of about 20$30 \%$ each year. One of the more significant biopolymers is polylactic acid (PLA), also known as polylactide, and as such it is the focus of this body of work.

In 1954, DuPont patented a high molecular weight PLA, and since that time many companies have begun to produce PLA on a wide scale. ${ }^{6}$ Although PLA was patented in 1954, its use was not fully realized until the late 1980's when Cargill, Inc. launched a 
project to develop PLA into a useful material for mainstream use. ${ }^{10}$ This project spurred the partnership with Dow Chemical and the launching of a joint venture between the two as Cargill Dow LLC, who would launch their PLA product under the name NatureWorks. In 2005 Cargill bought Dow's stake in the partnership and the company is now known simply as NatureWorks, with the PLA being marketed under the brand name Ingeo. ${ }^{11}$ Although there are many other companies who produce PLA (Apack AG, BASF, Bio Invigor, Birmingham Polymers, Boeringer Ingelheim, Hycail, Mitsui Chemicals, Phusis, Polysciences, Purac, and Shimadzu) NatureWorks is the largest. In 2002 NatureWorks finished construction of a major lactic acid plant, capable of producing over 300 million pounds of lactic acid and PLA per year.

\subsubsection{Lactic Acid and Lactide Monomer}

Lactic acid (2-hydroxypropionic acid), is the most widely occurring hydroxycarboxylic acid, and is used widely in food, pharmaceutical, textile, leather, and chemical industries. ${ }^{6}$ Lactic acid is produced in two ways, either via chemical synthesis or fermentation. Chemical synthesis of lactic acid is achieved by the hydrolysis of lactonitrile by strong acids, and this produces a racemic mixture of both the the L- and Dlactic acid. There are other methods by which to synthesize lactic acid, however, much focus is dedicated to synthesis via fermentation for several reasons. It is much more environmentally friendly due both to the lack of harsh chemicals and solvents as wells as the use of renewable sources for its synthesis. In addition to fermentation being highly selective in producing either the pure $\mathrm{L}(+)$ - or $\mathrm{D}(-)$ - lactic acid, it is much cheaper to synthesize this way because the substrates are cheap, production temperature is low, and 
energy consumption is low.

Many carbon sources are used for the microbial production of lactic acid. Sugars themselves can be used such as glucose, sucrose, lactose, etc., or sugar containing sources can be used such as molasses, whey, sugar cane, starchy materials from potato, wheat, etc. Many of these carbon sources are agricultural byproducts that have little use currently, so they are very cheap sources.

Lactide is derived either from the dehydration of lactic acid, heating an alkali

metal salt of 2-halopropionic acid, or via a method known as the KRICT process. ${ }^{12,13}$ In the KRICT process ammonium lactate or lactic acid is converted to an alkyl lactate which is then cyclized using a catalyst to generate an alcohol. Both lactide and lactic acid are both biocompatible and non-toxic and lactic acid is present in our bodies making these monomers environmentally friendly. ${ }^{14}$

\subsubsection{Polymerization and Synthetic Methods}

There are several methods which can be employed for the polymerization of polylactic acid. The main methods include the condensation of lactic acid, solid state polymerization, and various forms of ring opening polymerization.

\subsubsection{Condensation of Lactic Acid}

The structure of lactic acid, since it contains both and alcohol and a carboxylic acid group, allows it to undergo condensation polymerization. However, because this is an equilibrium reaction, high molecular weights are difficult to achieve unless organic solvents are used for the azeotropic distillation of water produced during the condensation polymerization process. Additionally, this reaction pathway is not ideal 
because the polymerization time to achieve high molecular weights is very long. High pressure reactions can also be used to increase the molecular weights of the polymers using this synthetic method. Using acid catalysts with this method allows for slightly higher molecular weights to be achieved, but at elevated temperatures, side reactions can occur. Polymerization via lactic acid condensation has shown to give a maximum molecular weight (number average, $M_{n}$ ) of about $3,000 \mathrm{~g} / \mathrm{mol}$, and up to $6,500 \mathrm{~g} / \mathrm{mol}$ for pure poly-L-lactic acid. ${ }^{6}$ Synthesis of PLA requires very pure monomer, since impurities interfere, especially water, with the course of the reaction. In addition, the monomer must be free of any contaminants containing a hydroxyl functionality, since alcohols are typically used to initiate the synthesis of PLA. Hydroxyl impurities cause an effect on the reaction through the reactions of initiator formation, chain transfer, and transesterification, which causes an increase in the rate of the reaction, as well as lowering molecular weight and broadening the molecular weight distribution of the final polymer. ${ }^{5}$ In addition to hydroxyl impurities being an issue, care must be taken to ensure no carboxylic groups are present, as these affect the reaction through a deactivation reaction by forming a complex with the catalyst (typically a transition metal catalyst), and lowering the rate of reaction. These impurities usually do not affect the final molecular weight of the polymer. ${ }^{5}$ The mechanism for the condensation of lactic acid is shown in Scheme 1.1. 
Scheme 1.1 Condensation polymerization mechanism.

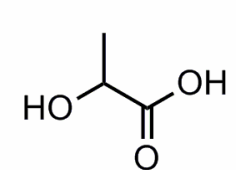

Lactic Acid

$\left.-\mathrm{H}_{2} \mathrm{O}\right\rfloor$ Condensation
Azeotropic

Dehydrative

Condensation

$-\mathrm{H}_{2} \mathrm{O}$
$>100,000 \mathrm{~g} / \mathrm{mol}$<smiles>C=C(O)C(C)OC(C)(C)C(=O)C(C)OC(C)(C)C(=O)C(C)O</smiles>

High MW PLA<smiles>C=C(O)C(C)OC(C)(C)C(=O)C(C)OC(C)(C)C(=O)C(C)O</smiles>

Low MW PLA

$\sim 1,000-5,000 \mathrm{~g} / \mathrm{mol}$

\subsubsection{Solid State Polymerization}

Solid state polymerization can also be employed for the synthesis of PLA. This process involves heating a semi-crystalline solid prepolymer of low molecular weight to a temperature above its glass transition temperature $\left(\mathrm{T}_{\mathrm{g}}\right)$ but below its melting temperature $\left(\mathrm{T}_{\mathrm{m}}\right)$. This allows for mobility of the chain ends, and the polymerization occurs mostly in the amorphous regions of the polymer. This method causes much slower rates of polymerization than other polymerization methods, but allows for very high molecular weight polymer to be synthesized. Also, because the reaction proceeds at a lower temperature than other methods, side reactions are less likely to occur. The reaction scheme for the solid state polymerization method is shown in Scheme 1.2. 
Scheme 1.2 Solid state polymerization of PLA<smiles>CC(O)C(=O)O</smiles>

Lactic Acid

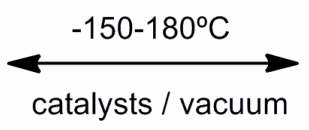

catalysts / vacuum<smiles>CC(C)OC(=O)C(C)(O)O</smiles>

Oligomer $\mathrm{n}=8-15$

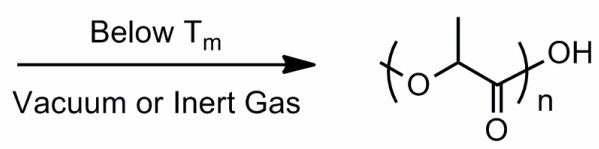

High MW PLA

\subsubsection{Ring Opening Polymerization}

The last major method for the synthesis of PLA is through ring opening polymerization. This can be done via three different methods: anionic, cationic, and a coordination-insertion mechanism. Anionic polymerization is initiated when the nucleophilic anion of the initiator attacks the carbonyl group of the lactide, which cleaves the carbonyl carbon and endocyclic oxygen bond. This oxygen becomes a new anion, which continues to propagate. ${ }^{5}$ This method, due to highly active catalysts at high temperatures, results in racemization, back biting action, and other side reactions. The reaction mechanism for the anion polymerization method is shown in Scheme 1.3.

Scheme 1.3 Anion polymerization mechanism

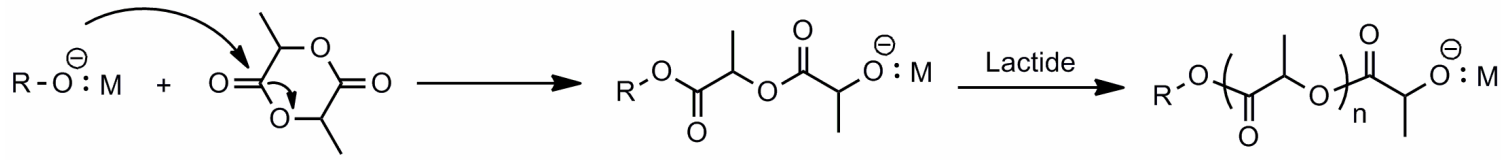

Cationic polymerizations are carried out when the exocyclic oxygen of one of the lactide carbonyls is either alkylated or protonated by the initiator, which causes the resulting $\mathrm{O}-\mathrm{CH}$ bond to become positively charged. Nucleophilic attack then occurs by a second monomer to break this bond and create another electrophilic carbenium ion, and 
thus the reaction propagates as additional monomers continue this attack. ${ }^{5}$ The reaction mechanism for the cationic polymerization method is shown in Scheme 1.4

Scheme 1.4 Cation polymerization mechanism

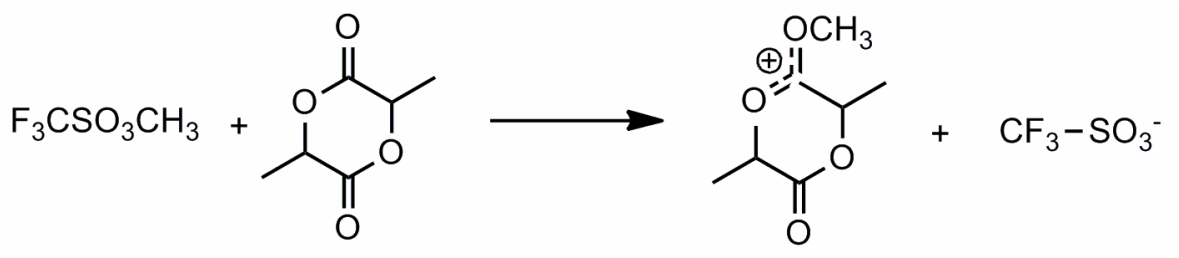<smiles></smiles>

The last type of ring opening polymerization is through a coordination-insertion mechanism, the most widely studied method in the literature for synthesis of high molecular weight polylactic acid, and is the type of polymerization carried out in this study. Many types of metal catalysts, which contain free $\mathrm{p}$ or d orbitals, are used for this type of polymerization, such as magnesium, tin, titanium, zirconium, and zinc alkoxides. While there are efforts being focused to develop titanium and zirconium catalysts for the ring opening polymerization of lactide ${ }^{15}$, stannous octoate is currently the preferred catalyst. Although stannous octoate is the most common catalyst for PLA, it is very toxic, and limiting its use would be of benefit to the growing market for PLA as a food packaging material.

The polymers in this study were synthesized using the tin based catalyst, stannous 
octoate, shown in Figure 1.1. The coordination-insertion mechanism is poorly understood, especially with regards to the initiating alcohol species. Theoretical studies, using methanol as the alcohol initiating species, have hypothesized that two molecules of the initiating alcohol coordinate with the stannous octoate catalyst and are favored by about $59-63 \mathrm{~kJ} / \mathrm{mol}$ and occur in associative fashion, i.e., with retention of the two octoate moieties. ${ }^{16,17}$ After the coordination of the alcohol species a weak complexation of lactide is then predicted with a coordination enthalpy of about $16 \mathrm{~kJ} / \mathrm{mol}$. This coordination step involves the proton transfer from the alcohol to the nearby octoate ligand, which converts the alcohol into an alkoxide. The insertion then occurs in two steps, namely, nucleophilic attack of the alkoxide on the coordinated lactide followed by ring opening, resulting formally in the insertion of a lactide moiety into the $\mathrm{O}-\mathrm{H}$ bond of a coordinated alcohol. The mechanism is shown in Scheme 1.5.

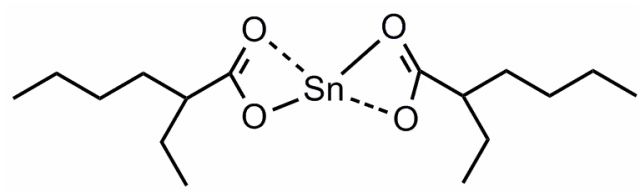

Figure 1.1 Structure of stannous octoate. 
Scheme 1.5 Coordination-insertion mechanism for polymerization of lactide with stannous octoate catalyst and generic alcohol initiating species.
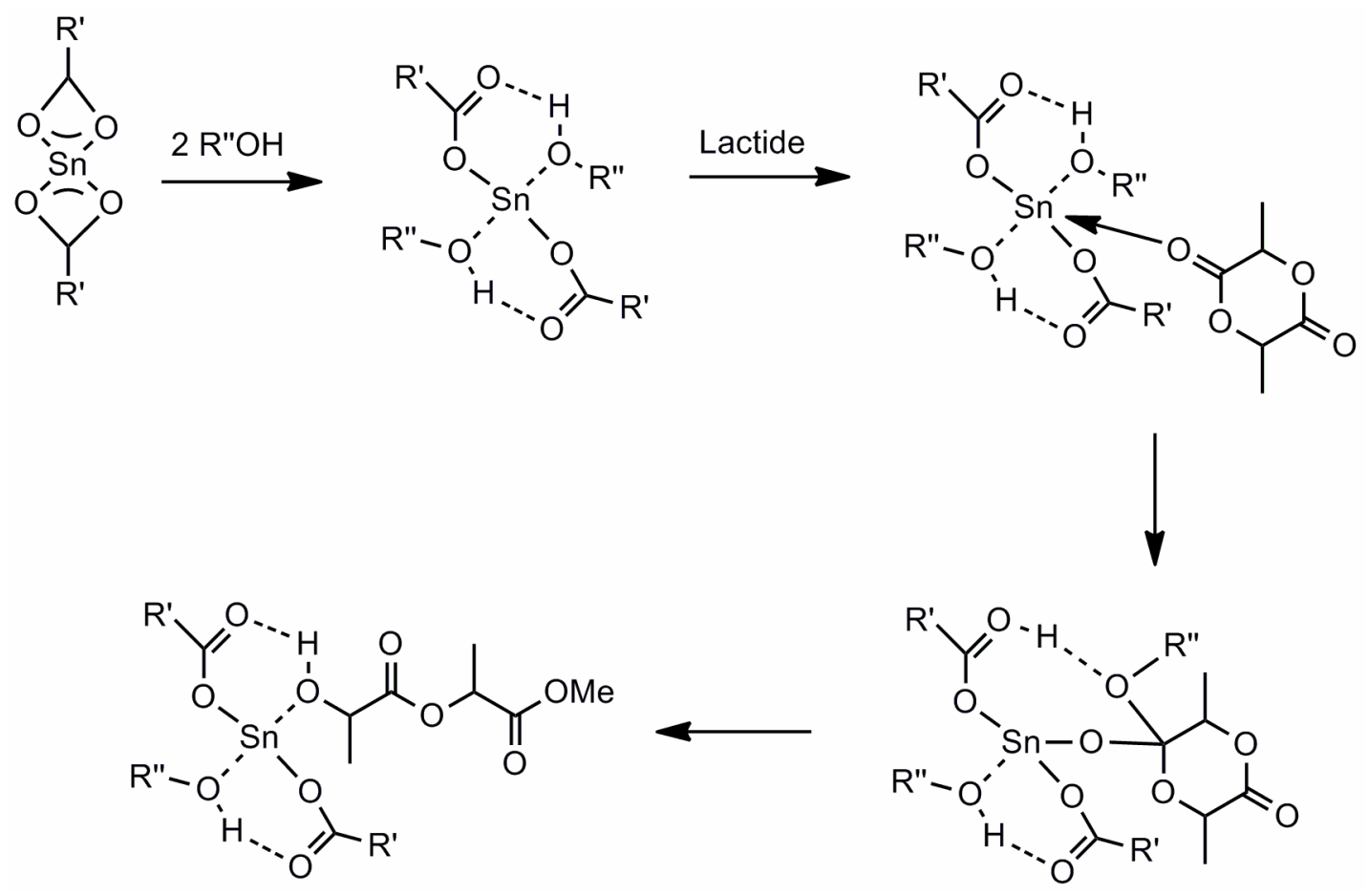

\subsubsection{Properties of PLA}

Polylactic acid is generally known for its good processability, biocompatibility, and biodegradability. However, due to the chirality present in the $\alpha$-carbon atom, L, D, and DL isomers of the polymer are possible. Physical and mechanical properties are greatly affected by the isomeric composition, as well as degradation rates. In addition to modifying the isomeric composition of the polymer to achieve different properties, molecular weight and molecular weight distribution play a large role in determining the properties of the polymer. The material properties of DL-PLA, compared with polystyrene and polyethylene terephthalate, are shown in Table 1.1. 
Table 1.1 Mechanical properties of PLA, compared with polystyrene and polyethylene terephthalate. ${ }^{5}$

\begin{tabular}{ccccc} 
Property & & \multicolumn{3}{c}{ Polymer } \\
Tensile strength & Unit & PLA & PS & PET \\
Elongation at break & {$[\mathrm{MPa}]$} & 68 & 45 & 57 \\
Flexural strength & {$[\%]$} & 4 & 3 & 300 \\
Flexural modulus & {$[\mathrm{MPa}]$} & 98 & 76 & 88 \\
Izod impact & {$[\mathrm{MPa}]$} & 3700 & 3000 & 2700 \\
Vicat softening point & {$\left[\mathrm{J} \mathrm{m}^{-3}\right]$} & 29 & 21 & 59 \\
Density & {$\left[{ }^{\circ} \mathrm{C}\right]$} & 58 & 98 & 79 \\
& {$\left[\mathrm{~g} \mathrm{~cm}^{-3}\right]$} & 1.26 & 1.05 & 1.4
\end{tabular}

The L isomeric form of PLA is often used when a high degree of crystallinity is required in the polymer. Because racemic polylactic acid is highly amorphous, it shows no melting point, and simply softens over a range of temperatures. Poly(L-lactic acid), however, can be made to be highly crystalline, specifically through annealing processes, and shows a melting range of about $170{ }^{\circ} \mathrm{C}$ to $183{ }^{\circ} \mathrm{C}$. In addition, the density of poly $\left(_{\mathrm{L}^{-}}\right.$ lactic acid) is slightly higher than for racemic PLA, at about $1.25-1.29 \mathrm{~g} / \mathrm{cm}^{3}$ compared to about $1.24 \mathrm{~g} / \mathrm{cm}^{3}$ for amorphous forms of PLA. ${ }^{5}$

\subsubsection{Applications of PLA}

Polylactic acid has been found to be useful in a wide array of applications since its inception, perhaps most notably, those in the biomedical realm. PLA has been used as resorbable medical implants and a material for tissue engineering in the shape of rod, plate, screw, fiber, sheet, rod, sponge, beads, and bone. ${ }^{18}$ Additionally, PLA has been used as films and foils for wound treatment. A major field of research involving PLA is its use as a drug delivery agent, ${ }^{19,20}$ and in similar fashion, pesticide and fertilizer releasing agent in agriculture. High molecular weight PLA may be used when the application requires a high amount of strength and structural integrity. However, the molecular 
weight and molecular weight distribution can be tailored to set the appropriate mechanical strength and degradation rate. For example, in the case of using PLA as a drug delivery agent, mechanical strength is not necessary, and high degradation rate is, so a low molecular weight polymer is used.

\subsubsection{Packaging Applications}

Polylactic acid has sparked interest in recent years as an alternative packaging material. Because it has properties similar to polyethylene terephthalate, which is an extremely common packaging material, it is of interest to both companies and consumers to replace PET with PLA. Consumers, now more than ever, demand that companies focus their efforts on becoming more sustainable and 'green.' One way in which a company can achieve this is through substituting its traditional petroleum based thermoplastics with renewable, biodegradable thermoplastics. The use of biodegradable plastics, especially in the fast food industry, is becoming increasingly more imminent in its implementation. Currently in the United States, $93 \%$ of waste generated by the fast food industry is potentially recoverable (i.e. 'recyclable'), yet only $29 \%$ is actually recovered each year. ${ }^{21}$ Paper based packaging represents a significant amount of the packaging market in the United States, as well as overseas. Paper accounts for $39 \%$ of the European packaging market, which sees 67 million tons of waste generated each year. ${ }^{22,23}$

Antimicrobial packaging is also a growing field. As consumers more frequently demand, fresh, ready-to-go meals, the challenges to prepare these food products safely are growing. To combat this issue, manufactures are increasingly using some form of antimicrobial packaging. One agent in use is lactic acid as an antimicrobial for defense 
against molds. ${ }^{24}$ PLA is often designed to have specific degradation rates. Antimicrobial agents such as nisin and propolis compounds have been incorporated into PLA and are designed to leach from the plastic at specific rates. ${ }^{25,26}$ Because lactic acid is the ultimate product of the biodegradation of PLA ${ }^{27}$ this could potentially be exploited for the use of PLA as an antimicrobial packaging material.

One of the main drawbacks of PLA for its use as an alternative packaging material is its poor gas barrier properties. In addition, to overcome the inherent brittleness of PLA, plasticizers are often used, which can further lower the gas barrier properties of PLA. To improve the gas barrier properties of PLA, nanocomposites such as kaolinite have been used. ${ }^{28}$ By blending kaolinite into the PLA, good interaction is observed, and an improvement in oxygen barrier properties by about $50 \%$ is observed. Mechanical properties of PLA can be significantly improved by nanocomposites as well. It has been demonstrated that various montmorillonite clays, at about 5 weight percent, can increase the tensile modulus and elongation at break of PLA by $36 \%$ and $48 \%$, respectively. ${ }^{29}$

\subsubsection{Hot Melt Adhesive}

Hot melt adhesives have become increasingly popular in the last decade because of their convenience and especially because of their environmentally friendly nature. Many adhesives contain solvents or an aqueous vehicle; hot melt adhesives contain neither. At room temperature, hot melt adhesives are solids, with heat become viscous, and cool rapidly once applied and bond very quickly to the substrate. So called 'warm-melt' adhesives have been developed which have similar properties as hot melt adhesives, but can be applied at room temperature. ${ }^{30}$ 
While many materials have been developed as hot melt adhesives, such as polyolefins, polyamides, ${ }^{31}$ polyurethanes, and polyesters, by far the most common are ethylene vinyl acetate copolymers (EVA). Typically an EVA hot melt will contain about 18-40 weight percent vinyl acetate. ${ }^{32}$ PLA has been used as a material for hot melt adhesives in the past, but is almost always blended with other polymers to improve its properties. For example, some PLA hot melts are blended with $19 \%$ poly( $\varepsilon$ -

caprolactone). ${ }^{33}$ Other biodegradable hot melt adhesives have been developed from poly( $\varepsilon$-caprolactone $)$ and soy protein isolate. ${ }^{34}$

\subsection{Purpose of this Study}

This study had two main objectives: develop a biodegradable, waterborne coating from polylactic acid, and to develop a hot melt adhesive based entirely from polylactic acid.

\subsubsection{Waterborne Coating}

The primary objective of this study was to develop a biodegradable, waterborne coating from polylactic acid. The main application for the intended coating is for fast food packaging containers, specifically to act as a grease barrier; similar work is being conducted with chitosan, however, treatment costs of this method remain high. ${ }^{35,36}$ Furthermore, the coating was to be spray applied. The purpose of this project is to develop a coating that can replace the traditional petroleum based thermoplastic coatings that are used currently on fast food packaging containers. Since corrugated paperboard and paperboard are biodegradable, the only portion of the package that is not is the current coating used. If a suitable coating could be designed, it would render the entire 
package as biodegradable. By replacing this coating with a biodegradable coating it would be a large selling point for a consumer market that is becoming increasingly more concerned with the environmental ramifications of the products they purchase. In addition, since a large majority of fast food waste is landfilled, this coating could potentially reduce the amount of non-biodegradable mass deposited in landfills.

The coating should also be spray applied. This application method offers several advantages over traditional lamination. First, very thin coatings can be easily applied by spray application. Also, with spray application, the coatings can be applied to the substrate after the package has been formed to its shape. By applying coatings to the substrate after the package has been formed, seams and corners can be covered with the coating, allowing for increased grease resistance.

\subsubsection{Hot Melt Adhesive}

A secondary objective of this study was to develop a hot melt adhesive from polylactic acid. Although PLA based hot melt adhesives have been reported, they are usually blends of PLA with other polymers. The objective of this portion of the study was to prepare a hot melt adhesive using solely PLA. This was achieved by blending different molecular weights of PLA together to achieve the desired properties. 


\section{Synthesis of Polylactic Acid (PLA)}

The waterborne coating was the primary objective of this project. A bulk polymerization technique was utilized to achieve a polymer with the desired properties. After a polymer was synthesized that was deemed to have the required properties, preparation of the coating formulation began. This represented a significant challenge and various ways to disperse the polylactic acid (PLA) were attempted, with the goal being to achieve the highest amount of dispersed solids as possible. Once the coatings were formulated, work was conducted to test the coatings ability to form a film and its properties were evaluated. The coating must form smooth films, have the ability to be spray coated, and most importantly, be grease resistant.

\subsection{Synthesis Methods}

Two polymerization methods were used throughout this project: bulk and solution. Bulk polymerization was used for the coating formulation portion of the project, and solution polymerization was used for the hot melt adhesive portion of the project.

\subsubsection{Bulk Polymerization}

Bulk polymerization was used for the coatings formulation portion of the project because of simplicity, and the ease of purification of the polymer. Previous experience showed that solution polymerization proved to be a very difficult polymerization method if pure polymer is the desired outcome. With solution polymerization the removal of solvent is very difficult, and thus, obtaining pure polymer is almost impossible. For this portion of the project, pure polymer was crucial because the exact contents and amounts of each ingredient in the coating formulation were vital. 
Conceptually, bulk polymerization is relatively simple. In bulk polymerization, monomer is added to the reaction flask, and in the case of lactide, heated until melted. After the monomer has melted, initiator and catalyst are added and the reaction is allowed to proceed. Bulk polymerization has drawbacks in that the viscosity of the reaction mixture is often very high, and consequently, heat transfer can be poor. In free radical polymerization, the lack of heat transfer often results in autoacceleration of the reaction, thus leading to a gel, also known as the Trommsdorff effect. ${ }^{37}$ In the case of polymerization of lactide in bulk, the latter is not an issue since it is a ring opening polymerization, so the reaction proceeds more slowly than with a free radical polymerization. High viscosity is a concern, so mechanical stirring must be utilized to ensure proper mixing of the reactants.

\subsubsection{Solution Polymerization}

The polymers obtained from solution polymerization were used for the hot melt adhesive. The variety of molecular weights and their morphology made them ideal for this application.

Conceptually, solution polymerization is only slightly more complicated than bulk polymerization. Solution polymerization requires that a non-reactive solvent is used in which the monomer and polymer are both soluble. Solution polymerization is often preferred over bulk polymerization because it reduces the viscosity of the polymerization as well as preventing autoacceleration at high monomer concentrations 


\subsection{Experimental}

\subsubsection{Materials}

Stannous octoate, 1-octanol, HPLC grade THF, glycerol, ethylene glycol, and lab grade toluene and hexanes were purchased from Sigma-Aldrich and used as received. D,L-Lactide was purchased from Purac, and was stored in a vacuum desiccator prior to use.

\subsubsection{Polymerization of Lactide in Bulk}

To a $250 \mathrm{~mL}$ three-neck round bottom flask was added D,L-lactide. Through the middle neck was attached an overhead, mechanical stirrer with teflon fins. To another neck was attached a vacuum adapter, and the other neck was capped with a rubber septum. The flask was vacuum-backfilled with nitrogen three times, then allowed to stir under vacuum for one hour. After stirring under vacuum, the flask was filled with nitrogen and was placed in an oil bath at a specific temperature. Once the lactide was completely melted, catalyst (in a solution in toluene) and the first initiator were added sequentially, via syringes through the rubber septum. The reaction time varied using the first initiator. After a given amount of time, a small sample was removed for analysis, and the second initiator was added in a similar manner as the first. After a given amount of time for the reaction to proceed with the second initiator, the reaction was removed from heat and poured from the flask to cool. Times, temperatures, and other reaction conditions are listed in Table 2.1. 
Table 2.1 Summary of the polymerization conditions for polymers synthesized in bulk.

\begin{tabular}{|c|c|c|c|c|c|c|}
\hline \multirow{2}{*}{ Sample } & \multirow{2}{*}{ Lactide (g) } & \multicolumn{2}{|c|}{$\begin{array}{c}\text { Monomer to Initiator } \\
\text { Ratio }\end{array}$} & \multirow{2}{*}{$\begin{array}{c}\text { Monomer to } \\
\text { Catalyst } \\
\text { Ratio }\end{array}$} & \multicolumn{2}{|c|}{ Reaction Times (h) } \\
\hline & & Glycerol & $\begin{array}{c}\text { Ethylene } \\
\text { Glycol }\end{array}$ & & Glycerol & $\begin{array}{c}\text { Ethylene } \\
\text { Glycol }\end{array}$ \\
\hline PLA $13^{a}$ & 50 & 157 & 39 & 12355 & 5.50 & 12 \\
\hline PLA 14 & 50 & 634 & 39 & 12355 & 5.00 & 12 \\
\hline PLA 15 & 50 & 634 & 39 & 12355 & 2.75 & 12 \\
\hline PLA 16 & 50 & 52 & 39 & 12355 & 2.20 & 2.8 \\
\hline PLA $17^{b}$ & 50 & 157 & 39 & 12355 & 2.20 & 2.8 \\
\hline PLA 18 & 25 & 78 & 20 & 12221 & 2.00 & 3.5 \\
\hline PLA 19 & 25 & 72 & 40 & 12221 & 2.00 & 4.3 \\
\hline PLA 20 & 25 & 72 & 40 & 12221 & 2.00 & 4.3 \\
\hline PLA 21 & 25 & 507 & 40 & 12221 & 3.00 & 17 \\
\hline PLA 22 & 25 & 254 & 40 & 12221 & 3.00 & 17 \\
\hline PLA 23 & 50 & 507 & 39 & 6773 & 3.00 & 12 \\
\hline PLA 24 & 50 & 254 & 39 & 6773 & 2.00 & 12 \\
\hline PLA 25 & 50 & 169 & 78 & 6773 & 0.75 & 12 \\
\hline PLA 26 & 50 & 127 & 48 & 6773 & 0.50 & 12 \\
\hline PLA 27 & 50 & 127 & 48 & 6773 & 0.50 & 12 \\
\hline PLA 28 & 50 & 85 & 48 & 6773 & 0.50 & 12 \\
\hline PLA 29 & 25 & 85 & 48 & 6246 & 0.50 & 12 \\
\hline PLA 30 & 125 & 85 & 65 & 8031 & 0.50 & 12 \\
\hline PLA 31 & 125 & 85 & 97 & 8031 & 0.33 & 12 \\
\hline PLA 32 & 125 & 85 & 65 & 8031 & 0.33 & 12 \\
\hline PLA 33 & 125 & 85 & 97 & 8031 & 0.25 & 12 \\
\hline PLA 34 & 125 & 70 & 65 & 8031 & 0.33 & 12 \\
\hline PLA 35 & 125 & 106 & 48 & 8031 & 0.50 & 12 \\
\hline PLA 36 & 125 & 127 & 61 & 8031 & 0.33 & 12 \\
\hline PLA 37 & 300 & 127 & 61 & 8031 & 0.50 & 12 \\
\hline PLA 38 & 300 & 117 & 58 & 8031 & 0.17 & 12 \\
\hline PLA 43 & 300 & 127 & 61 & 8031 & 0.20 & 12 \\
\hline
\end{tabular}

All PLA samples in this table were polymerized at $140{ }^{\circ} \mathrm{C}$ unless otherwise noted $\left(a, 135{ }^{\circ} \mathrm{C}, b, 180{ }^{\circ} \mathrm{C}\right)$. All samples listed in this table were polymerized using the dual initiator system, with glycerol and ethylene glycol.

\subsubsection{Polymerization of Lactide in Solution}

To a $250 \mathrm{~mL}$ Schlenk flask was added D,L-lactide ( $50 \mathrm{~g}, 0.347 \mathrm{~mol})$ and a Teflon coated stir bar. The top of the flask was sealed with a rubber septum, and the side arm was connected to a vacuum line. The flask was vacuum backfilled with nitrogen three 
times, and then evacuated and stirred for 1 hour at room temperature. The flask was then heated to $50{ }^{\circ} \mathrm{C}$ and stirred for an additional hour, still under vacuum. The flask was then filled with nitrogen and toluene $(50 \mathrm{~mL})$ was added through a gastight syringe. 1-octanol (varying amounts), and stannous octoate solution (1 mL, $0.062 \mathrm{mmol})$, prepared by mixing stannous octoate $(200 \mu \mathrm{L}, 0.617 \mathrm{mmol})$ in toluene $(10 \mathrm{~mL})$ resulting in a $0.062 \mathrm{M}$ solution, were introduced sequentially through the septum via gastight syringes. The temperature was then increased to $80^{\circ} \mathrm{C}$ and the mixture was allowed to stir for 20 hours. The mixture was then diluted into 1 liter of toluene and precipitated into 3 liters of cold hexanes. Solids were collected by vacuum filtration and the resulting polymer was dried at $75^{\circ} \mathrm{C}$ for one week to remove remaining solvent. The polymer was analyzed by GPC, DSC, and TGA. The various reaction conditions are listed in Table 2.2

Table 2.2 Summary of the polymerization conditions for polymers synthesized in solution.

$\begin{array}{cc}\text { Sample } & \text { Monomer to Initiator Ratio } \\ \text { PLA 1 } & 110 \\ \text { PLA 6 } & 62 \\ \text { PLA 7 } & 219 \\ \text { PLA 8 } & 93 \\ \text { PLA 9 } & 155 \\ \text { PLA 10 } & 280 \\ \text { PLA 11 } & 249 \\ \text { PLA 12 } & 137 \\ \text { Initiator and catalyst used were 1-octanol and stannous octoate respectively. Conditions were solution } \\ \text { polymerization at } 80{ }^{\circ} \text { C, 50g lactide, monomer to catalyst ratio of 5620:1, and 20 hour reaction time. }\end{array}$

\subsection{Results and Discussion}

\subsubsection{Bulk Polymerization}

Results of the polymerizations will be discussed in this section. For results and discussion pertaining to the performance and behavior of these polymers as coatings, see 
section 3.4.

These polymers were synthesized to have specific molecular weights and molecular weight distributions (MWD). For reasons described in greater detail in section 2.2, the polymers were designed to contain both high molecular weight $(20-50 \mathrm{k} \mathrm{g} / \mathrm{mol})$ tribranched polymer chains, as well as low molecular weight $(5-15 \mathrm{~kg} / \mathrm{mol})$ linear chains. Glycerol was used as the initiator for the branched polymer (although isocyanates, phenyl phosphites, and epoxies can be used as initiators for this purpose, ${ }^{38}$ glycerol has demonstrated its effectiveness as an initiator for creating tribranched PLA) ${ }^{39}$ and ethylene glycol was used as the initiator for the linear polymers. A summary of the final molecular weights and MWDs obtained for the polymers synthesized is shown in Table 2.3.

The fundamental idea behind dispersing the PLA is to broaden molecular weight distribution by creating a bimodal MWD. By creating a polymer with a bimodal MWD, there will be some chains of high molecular weight which are tri-branched in structure, and some that are low molecular weight and linear in structure. The tri-branching allows for the mechanical properties of a high molecular weight polymer, but is easier to disperse as the polymer is unable to interact with itself intramolecularly to the same degree as if it were the same molecular weight and linear. In other words, decreased chain entanglement will occur for a branched polymer. This is discussed further in section 3.1. This allows the various components of the formulations to interact more easily with the polymer, thus dispersing it. The low molecular weight linear portions also act to give the polymer desirable properties and allow for easier dispersion. The low molecular weight chains can act as internal plasticizers, which will give the coating the desired flexibility, 
and allows for less addition of components to the formulation.

Table 2.3 Summary of the final molecular weights obtained for the polymers synthesized in bulk.

\begin{tabular}{ccr} 
Sample & $\mathbf{M}_{\mathbf{n}}(\mathbf{g} / \mathbf{m o l})$ & PDI \\
PLA 13 & 17000 & 1.17 \\
PLA 14 & 1600 & 4.53 \\
PLA 15 & 6300 & 2.52 \\
PLA 16 & 2900 & 1.49 \\
PLA 17 & 6700 & 1.18 \\
PLA 18 & 2900 & 1.18 \\
PLA 19 & 8600 & 1.12 \\
PLA 21 & 1700 & 1.61 \\
PLA 23 & 28000 & 1.27 \\
PLA 24 & 13000 & 1.44 \\
PLA 26 & 9100 & 1.59 \\
PLA 27 & 1900 & 1.15 \\
PLA 29 & 4800 & 1.73 \\
PLA 30 & 9200 & 1.17 \\
PLA 31 & 7700 & 1.39 \\
PLA 32 & 7200 & 1.23 \\
PLA 33 & 8900 & 1.13 \\
PLA 34 & 6500 & 1.17 \\
PLA 35 & 8700 & 1.18 \\
PLA 36 & 7000 & 1.24 \\
PLA 37 & 6000 & 1.40 \\
PLA 38 & 6700 & 1.27 \\
PLA 39 & 3800 & 1.24 \\
PLA 40 & 1900 & 1.22 \\
PLA 42 & 500 & 1.31 \\
PLA 43 & 9100 & 1.13 \\
\hline PLA & &
\end{tabular}

The molecular weight given is the number average molecular weight as calculated by GPC.

A multiple initiator synthetic procedure was employed to achieve this goal.

Multifunctional initiators are being used to create branched structures of high molecular weight. When the polymerization has proceeded to a given extent, but is not at completion, a second mono or bifunctional initiator is injected into the reaction flask to create low molecular weight chains and oligomers.

All PLA resins were synthesized in bulk to ensure that any formulations created from our newly synthesized PLA contain known amounts of all constituents and that there is 
no solvent present in the samples (complete removal of all solvent from solution-based polymerization is very difficult).

Molecular weights, as determined by gel permeation chromatography (GPC) matched theoretical values. After the first initiator, the number average molecular weight $\left(M_{n}\right)$ is higher than after the reaction with the second initiator. This indicates that the first initiator, glycerol, is producing a high molecular weight branched structure as desired. Then after the reaction with the second initiator, smaller, low molecular weight species are being produced, as evident by the reduction in molecular weight, and the increase in the polydispersity index (PDI), as shown in Table 2.4.

Table 2.4 Summary of changes in molecular weight and molecular weight distribution for various PLA samples.

\begin{tabular}{ccccc} 
Sample & $\begin{array}{c}\mathbf{M}_{\mathbf{n}} \mathbf{( g / m o l )} \\
\text { (after initiator 1) }\end{array}$ & $\begin{array}{c}\mathbf{M}_{\mathbf{n}} \mathbf{( g / m o l )} \\
\text { (after initiator 2) }\end{array}$ & $\begin{array}{c}\text { PDI } \\
\text { (after initiator 1) }\end{array}$ & $\begin{array}{c}\text { PDI } \\
\text { (after initiator 2) }\end{array}$ \\
\hline PLA 14 & 13000 & 1630 & 1.35 & 4.53 \\
PLA 15 & 29500 & 6320 & 1.07 & 2.52 \\
PLA 16 & 3440 & 2877 & 1.16 & 1.49 \\
PLA 23 & 37450 & 27687 & 1.12 & 1.27 \\
PLA 24 & 31136 & 12765 & 1.16 & 1.44 \\
PLA 27 & 17401 & 1890 & 1.15 & 4.89
\end{tabular}

Figures 2.1 through 2.4 illustrate this shift in MWD. In some cases the shift in $M_{n}$ and MWD distribution were subtle, and in other cases the shift was large. The factors contributing to these shifts are numerous, and more rigorous study would be required to fully characterize these factors. Possible variables might include, reaction time after each initiator (RT1 and RT2), amount of each initiator, and total mass of monomer being the most significant of the variables. Concentration of catalyst, although likely a factor in the MW and MWD shift, was not thoroughly investigated in this study. 
The only variable changed between samples PLA 14 and PLA 15 were the reaction time while only the first initiator was present. Sample PLA 14 RT1 was 5 hours, whereas the PLA 15 RT1 was only 2.75 hours. Although the concentration of initiator present in each sample remained the same, the molecular weights were quite different between the two samples. Figure 2.1 shows the GPC traces of PLA 14 and 15. The plot for PLA 14 shows that there are many more chains of low molecular weight, as indicated by the PDI for the final PLA 14 being 4.53 compared to 2.52 for the final PLA 15. Because in PLA 14 RT1 is about twice as long as RT1 in PLA 15, by the time the second initiator is injected into the reaction flask much more monomer has been consumed, leading to an overall lower molecular weight, which increases the PDI, as seen in Table 2.3

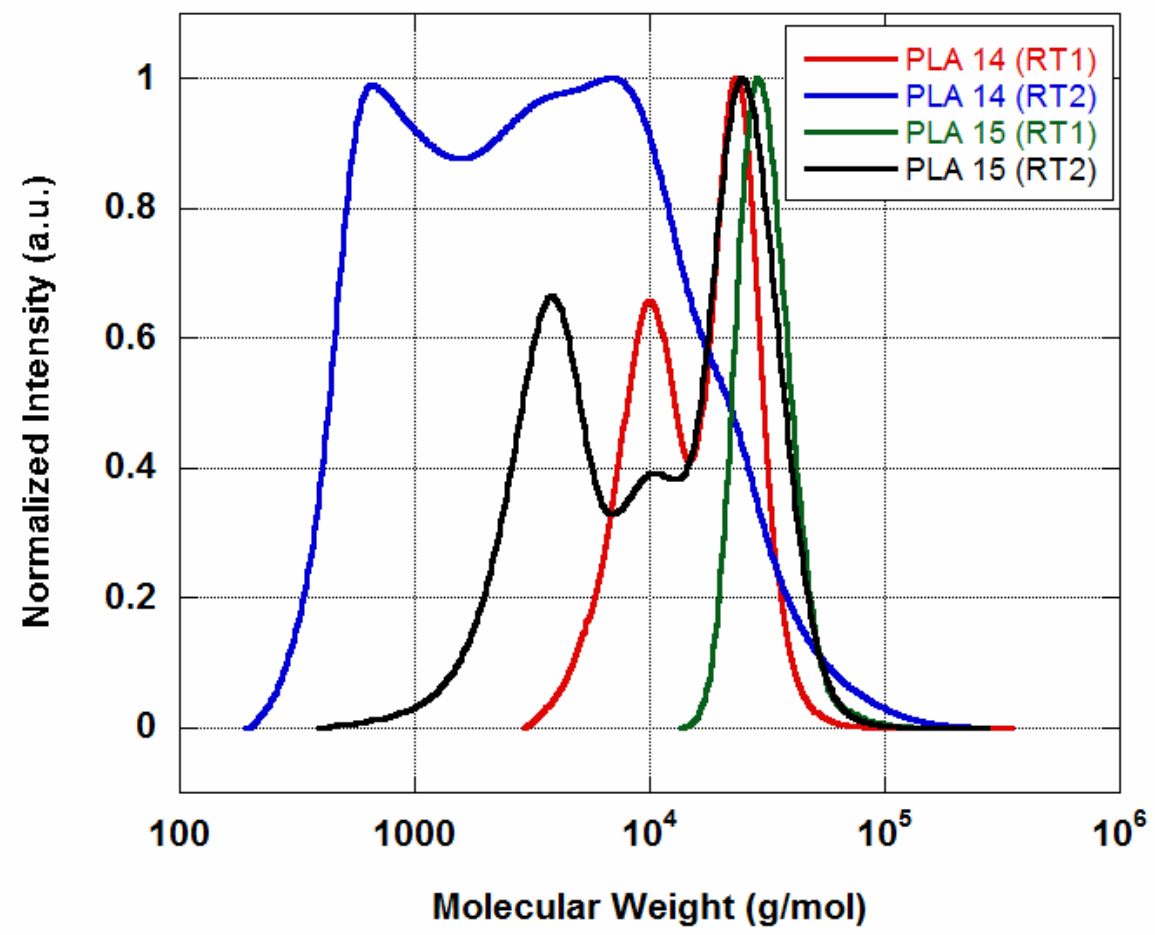

Figure 2.1 GPC analysis of PLA 14 and PLA 15. Red - PLA 14 after polymerization with first initiator. (RT1). Blue - PLA 14 after polymerization with second initiator (RT2). Green - PLA 15 after polymerization with first initiator. (RT1). Black - PLA 15 after polymerization with second initiator (RT2). 
In PLA 16, as shown in Figure 2.2, several variables are changed, most notably overall reaction time. In PLA 14 and 15, the total reaction times were about 17 and 15 hours, respectively. In PLA 16, the overall reaction time was about 5 hours, which is very well illustrated in an examination of Table 2.3. The molecular weights after both initiators are significantly less than in both PLA 14 and 15. Characteristically, the molecular weight is reduced after the injection of the second initiator due to formation of low molecular weight chains; the MWD also broadens similarly. Of interest to note are the identities of oligomeric chains in the PLA 16 sample. On the GPC trace seen in Figure 2.3 for PLA 16B indicated in blue, dimers, trimers, tetramers, etc. can be seen on the trace.

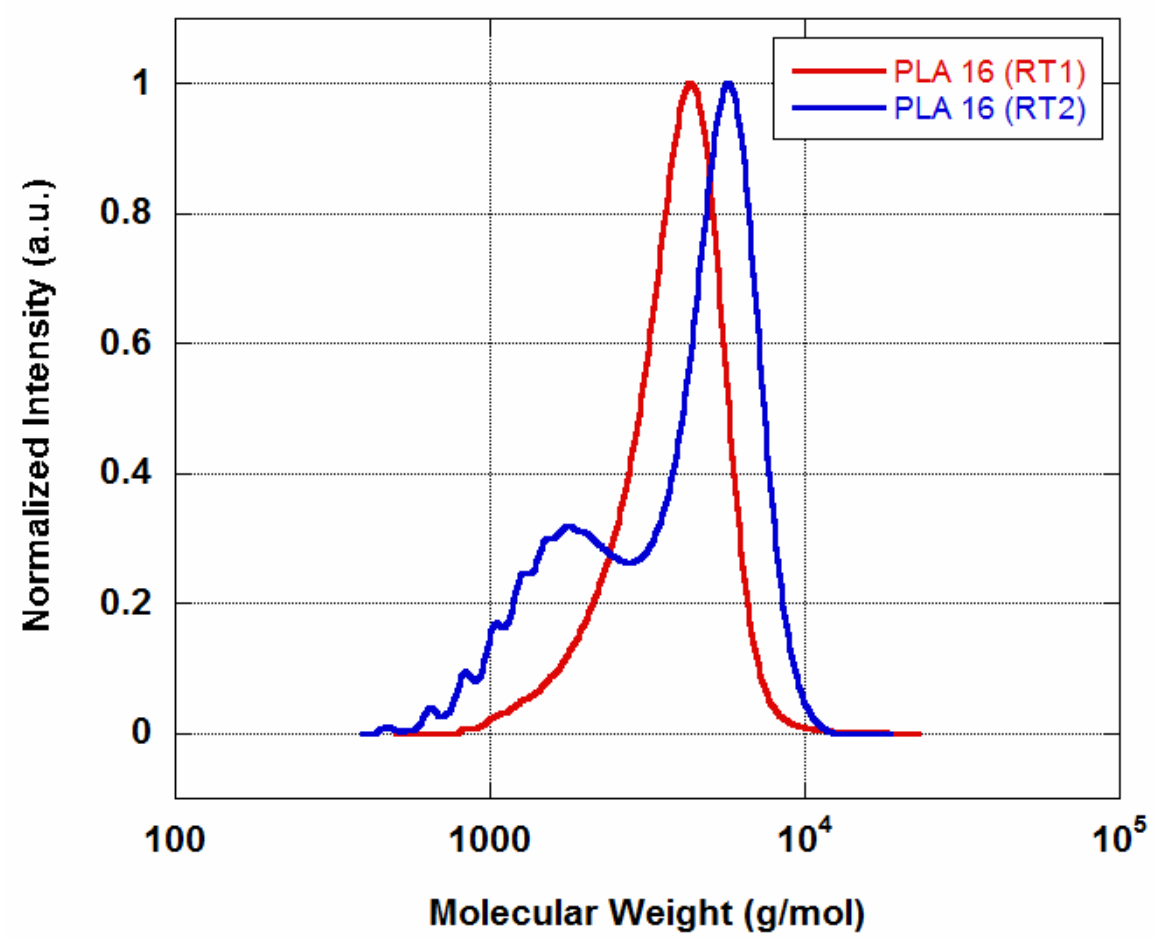

Figure 2.2: GPC analysis of PLA 16. Red - sample after polymerization with first initiator. (RT1). Blue sample after polymerization with second initiator (RT2). Note the oligomeric chains seen in the trace for after the polymerization with the second initiator. 


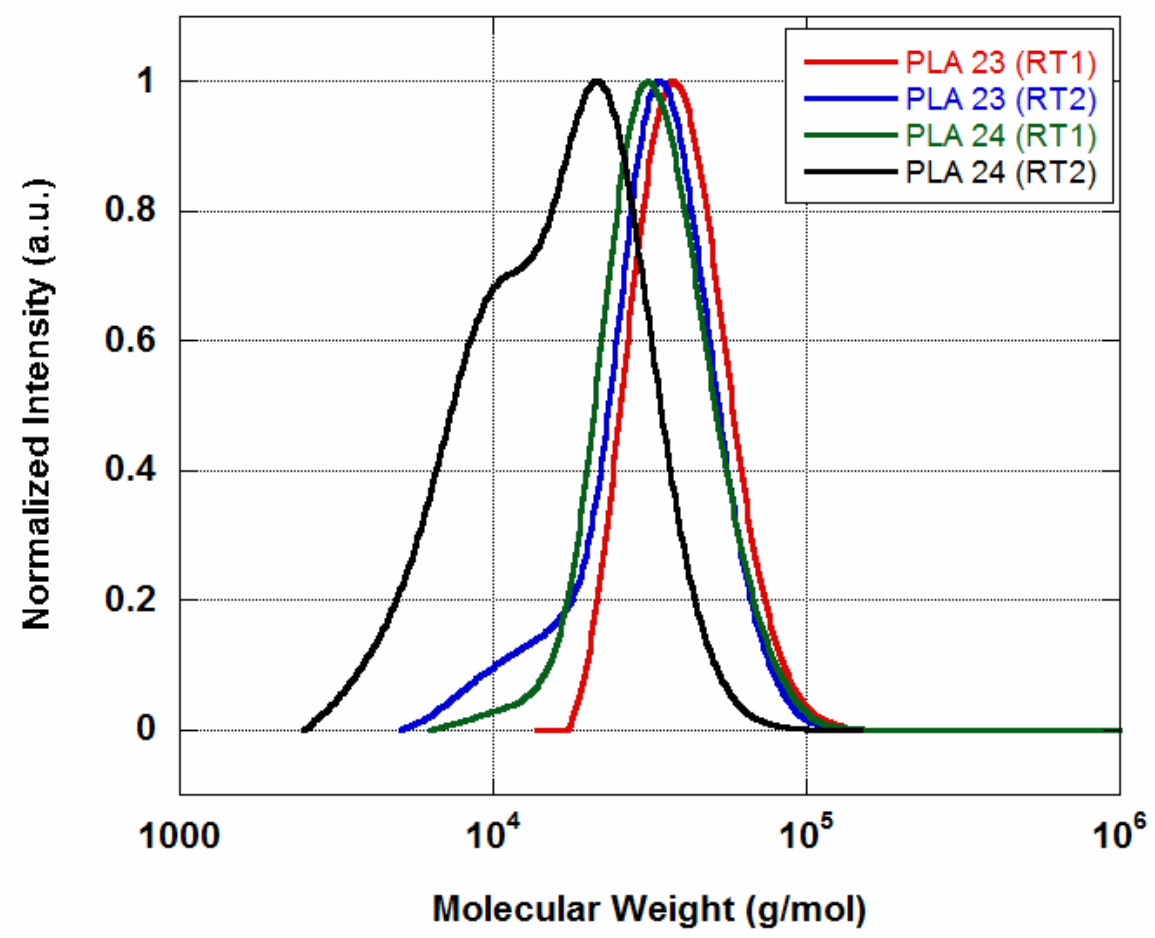

Figure 2.3 GPC analysis of PLA 23 and PLA 24. Red - PLA 23 after polymerization with first initiator. (RT1). Blue - PLA 23 after polymerization with second initiator (RT2). Green - PLA 24 after polymerization with first initiator. (RT1). Black - PLA 24 after polymerization with second initiator (RT2).

Shown in Figure 2.3 are samples PLA 23 and 24. There were two significant difference between samples PLA 23 and PLA 24: about twice as much initiator 1 was used in PLA 24, and RT1 for PLA 24 was about one third less. The most striking difference seen in the data in Table 2.3 is that PLA 23 has an overall higher molecular weight. This is due to increased RT1, and lower initiator concentration for this sample. 


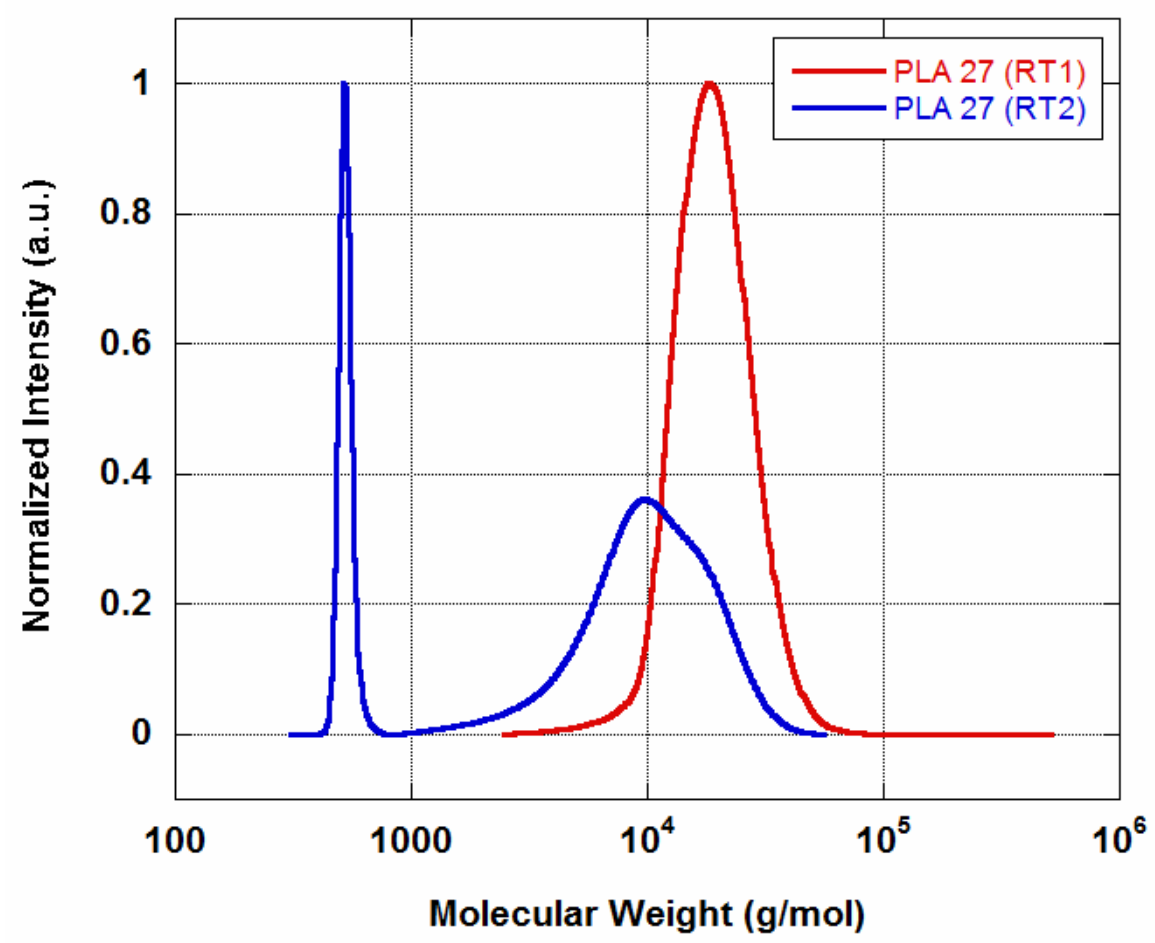

Figure 2.4 GPC analysis of PLA 27. Red - sample after polymerization with first initiator. (RT1). Blue sample after polymerization with second initiator (RT2).

Sample PLA 27, Figure 2.4, shows a very interesting GPC trace. A very small RT1 was used in this sample, allowing for a high amount of monomer to be present during polymerization with initiator 2 , which is the reason for the large increase in PDI observed.

Creating a bimodal distribution is easily accomplished by varying the initiator concentrations and injection times. In general a broader MWD will be realized when there is a higher amount of monomer present when the second initiator is injected. Another way to broaden MWD is to vary the concentrations of each initiator such that very high molecular weight species are formed as well as very low molecular weight species. For example, if a low concentration of initiator 1 is used, then the resulting polymer will be high molecular weight, and if a high concentration of the second initiator 
is introduced, then the resulting chains will be of low molecular weight, thereby broadening the MWD of the final polymer.

There is an added benefit of the polymerization of a bimodal polymer which contains low molecular weight linear chains in that they can act as a plasticizer. The low molecular

weight linear chains can break up aggregates of the larger PLA particles. Since the idea of the tribranched polymer is to reduce aggregation, the low molecular weight chains are an added benefit. They also allow for less actual plasticizer to have to be added to the coating formulation, reducing complication and also reducing cost.

\subsubsection{Solution Polymerization}

Polymers of various molecular weights were synthesized and are detailed in Table 3.2. Polymers having as low as $3,400 \mathrm{~g} / \mathrm{mol}$ and as high as $47,000 \mathrm{~g} / \mathrm{mol}$ molecular weight were synthesized. Although there was a large range in molecular weights, hardness values (as determined qualitatively by hand) varied in an uncorrelated manner. Hardness for these samples was much more dependant on residual solvent than molecular weight. In addition, residual solvent depended largely on how well the precipitation of the polymer was performed. For many of these samples, the way in which this was performed varied. Different approaches (various ratios of toluene to hexanes, rate of addition, temperature of solutions and solvents, etc.) were utilized, but not enough data was collected to determine the best approach to yield clean polymer. As a result some polymer had more entrapped solvent than others. This, however, was useful in some ways, as the solvent present allowed for an extremely tacky polymer, useful for a hot melt adhesive. 
The polymers prepared by solution polymerization yielded very monodispersed samples. The highest PDI obtained was 1.27, which was also the first polymer synthesized in this study. As synthetic technique was improved in the subsequent samples, PDI less than 1.05 were obtained, as seen in Table 2.5.

Table 2.5 Summary of the molecular weights and PDI of the polymers synthesized for use as a hot melt adhesive.

$\begin{array}{ccr}\text { Sample } & \mathbf{M}_{\mathbf{n}}(\mathbf{g} / \mathbf{m o l}) & \text { PDI } \\ \text { PLA 10 } & 47,000 & 1.18 \\ \text { PLA 11 } & 43,000 & 1.11 \\ \text { PLA 12 } & 33,000 & 1.17 \\ \text { PLA 9 } & 30,000 & 1.10 \\ \text { PLA 1 } & 21,000 & 1.27 \\ \text { PLA 8 } & 11,000 & 1.03 \\ \text { PLA 6 } & 10,000 & 1.08 \\ \text { PLA 7 } & 3,400 & 1.06 \\ \text { Molecular weight is given as the number average molecular weight as calculated by } & \text { GPC. }\end{array}$

\subsection{Conclusions}

Polymers of various molecular weights were successfully synthesized using bulk polymerization techniques. Using a multiple initiator system, tailored polymeric architectures and molecular weight distributions could be obtained. Using the first initiator, glycerol, high molecular weight, tri-branched PLA was synthesized; then, after an injection of glycerol at a given time after the polymerization had begun, low molecular weight linear chains could be synthesized.

Polymers of various molecular weights and narrow molecular weight distributions were successfully synthesized using solution polymerization techniques. 


\section{Coating Formulation}

An objective of this study was to create a waterborne coating from polylactic acid.

The inherent difficulty in this task is that PLA is not water soluble. So in order to create a waterborne coating from PLA, the polymer must be dispersed. The basic principle behind this is to encapsulate the polymer particles in a surfactant which will have a hydrophobic tail which will interact favorably with PLA and a hydrophilic tail which is soluble with water, as illustrated in Figure 3.1.

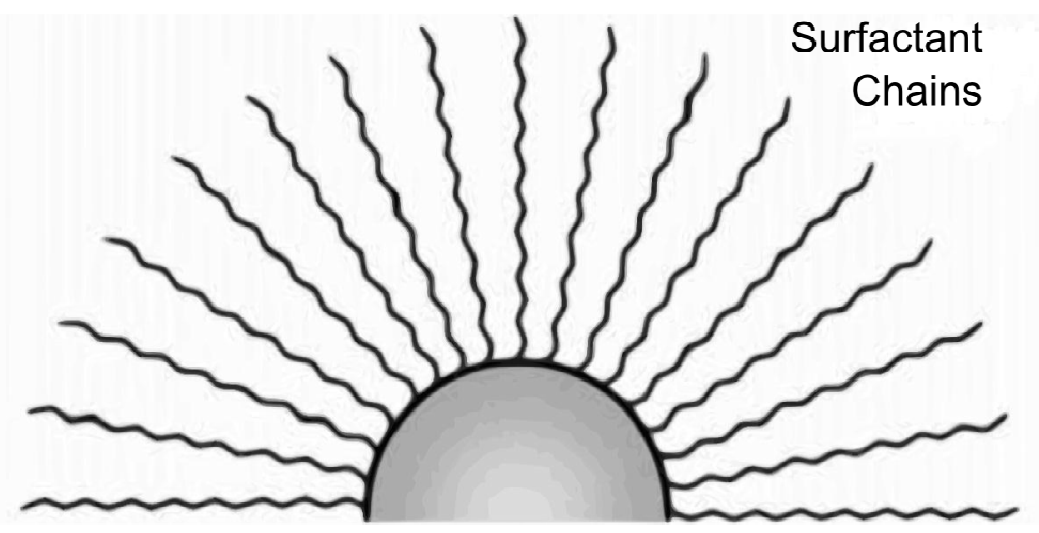

PLA Particle

Figure 3.1 Schematic view of a PLA particle interacting with surfactant chains (not to scale) [Modified from Pelligrino $]^{40}$

Encapsulating hydrophobic particles in a surfactant to solubilize them in water is a common practice (washing food grease off your hands with dish soap is an example), but the challenge is significantly increased when the particle is a polymer. The molecular weights of the polymers used in this study range from $5,000 \mathrm{~g} / \mathrm{mol}$ to $45,000 \mathrm{~g} / \mathrm{mol}$. Because of this one polymer chain will have a very large amount of hydrophobic groups. The biggest problem, however, is that because the polymer chain is so long, it will coil around itself in the case of PLA and water. Since PLA contains hydrophobic groups it 
will form a roughly spherical shape to minimize its interaction with water. Surfactants exist which will interact with the ester groups on $\mathrm{PLA},{ }^{41}$ but when the conformation of the polymer does no allow access to these groups a thorough encapsulation will be very difficult, and the polymer particle will simply precipitate.

\subsection{Polymeric Architecture}

A relatively high molecular weight polymer must be used to ensure desirable mechanical and thermal properties of the end-use product. In general, the higher the molecular weight, the longer the polymer chain becomes. While this is true in a sense, there are ways in which this problem can be circumvented. In a linear chain this is certainly true of polymers, but not necessarily the case if the polymer backbone contains branching points, or is of some type of star-shape. Designing a polymer in this fashion allows for an increase in molecular weight, and thus overall properties of the polymer, without having to create a very long chain polymer. While this is true to a degree, it must be noted that an equal molecular weight linear polymer will have better physical

properties than a branched polymer. ${ }^{42}$ The benefit of this is that the polymer chains will have less ability to form intramolecular conformations. A high molecular weight polymer will have been synthesized, but behaves similarly to a low molecular weight polymer in terms of its hydrodynamic volume. In this study, a tri-branched polymer system was utilized, as shown in Scheme 3.1. 
Scheme 3.1 Synthetic route for the preparation of linear and branched polylactic acid polymers.

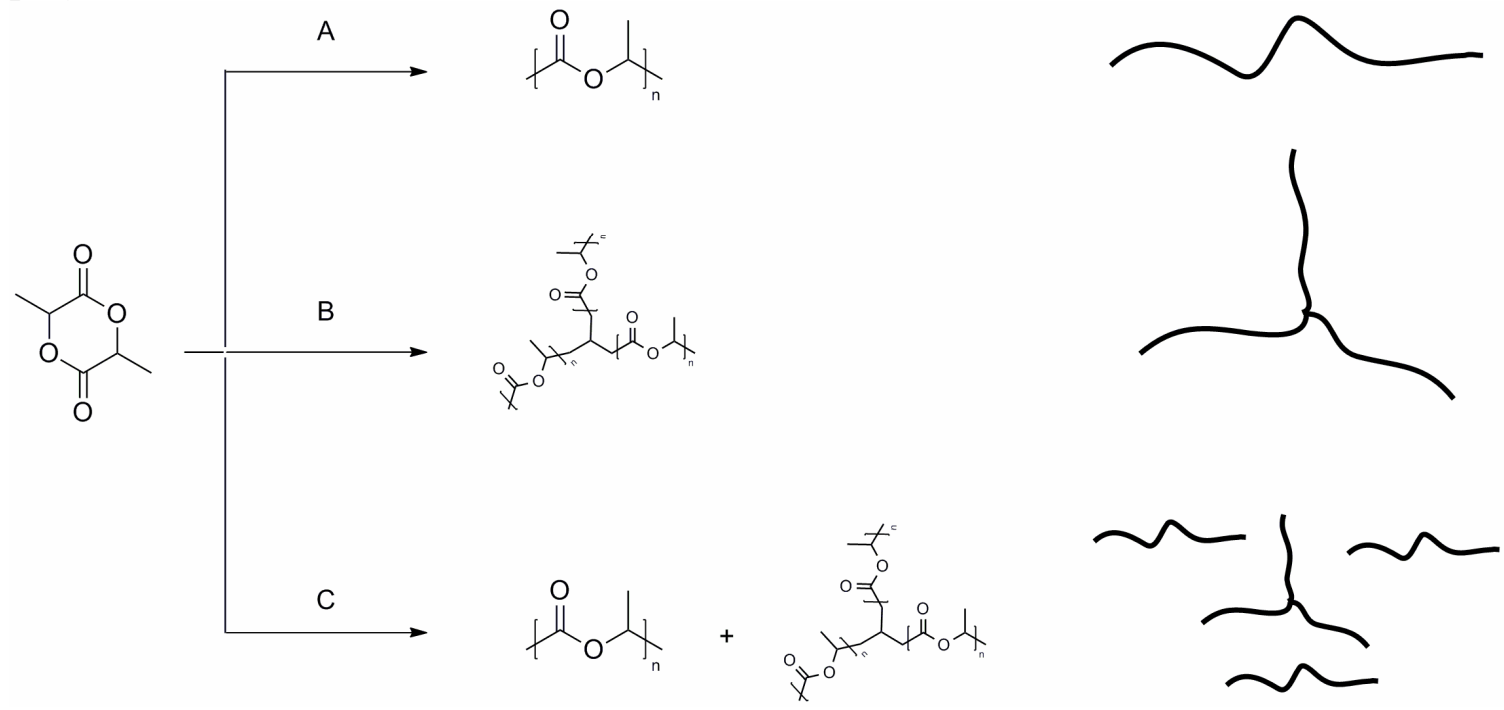

Conditions: A) Ethylene glycol, stannous octoate, $140{ }^{\circ} \mathrm{C}$; B) Glycerol, stannous octoate, $140{ }^{\circ} \mathrm{C} ; \mathrm{C}$ ) Glycerol, stannous octoate, $140{ }^{\circ} \mathrm{C}$, then addition of ethylene glycol.

The objective now is to determine the best way to encapsulate the PLA particle in surfactant in order to best solubilize it in water. Several methods are explored in this study, finally leading to one method which realized a degree of success as illustrated by the final coating performing its role as a grease resistant barrier for paper packaging.

\subsection{Experimental}

Various methods were employed to attempt to disperse PLA. For the sake of clarity these methods will be introduced in chronological order, as performed during the course of this study.

\subsubsection{Materials}

The materials listed in this section are inclusive of all materials used throughout the portion of the project entitled 'Waterborne Coating.' 1-Octanol, stannous octoate, HPLC grade toluene, lab grade toluene, lab grade hexanes, HPLC grade THF, lab grade 
dichloromethane, glycerol, ethylene glycol, and lab grade acetone were purchased from Sigma-Aldrich and used as received. D,L-Lactide was purchased from Purac, and was stored in vacuum desiccator prior to use. Triton X-200 and Triton X-100 were purchased from DOW, and used as received. Surfynol 104H was purchased from Air Products and used as received. Hexamoll DINCH, Plastomoll DOA, and Palatinol DPHP were purchased from BASF and used as received. Corrugated paperboard was supplied from a commercial source.

A TA Instruments Q-Series DSC was used to perform differential scanning calorimetry analysis of the samples. A TA Instruments Q-Series TGA was used to perform thermal gravimetric analysis of the samples. An Agilent 1200 RI liquid chromatograph using PSS WinGPC Unity software was used to perform gel permeation chromatography of the samples. A Bird Type 1-8 mil drawdown bar and BYK byko-charts were used to make the films of the dispersions. A Thermo Scientific Fourier-transform infrared spectrometer using a zinc-selenium crystal was used to perform infrared spectroscopy on the samples. A Buchi Rotary Evaporator was used to remove the solvent from various samples. A US Composites E\&S Model 100 Gelcoat Dump/Spray Gun was used to spray coat the corrugated paperboard samples.

\subsubsection{Methods}

\subsubsection{Hot Dispersion}

The hot dispersion technique was the first, and accordingly, the most rudimentary of the dispersion techniques attempted. 


\subsection{General Procedure for Hot Dispersion}

The procedure for the hot dispersion technique evolved slightly through its process, but in general the procedure involved adding a water and surfactant mixture to a hot molten PLA which had been prepared in bulk. As the methods improved the addition of water in its rate or order were changed slightly, and various ingredients were added, such as plasticizers and dispersion aids (various hydrolyzed polyvinyl acetates).

\subsection{Hot Dispersion Procedure for Samples PLA 13 - PLA 18}

Using the synthetic procedures outlined in section 2.2.2, PLA was synthesized in bulk. After a given amount of time for the reaction to proceed with the second initiator, a sample was removed for analysis and then surfactant was added to the reaction flask and allowed to stir for one hour. Samples PLA 13 - PLA 15: in a separate $250 \mathrm{~mL}$ 3-neck round bottom flask attached to a mechanical stirrer with Teflon coated stirrer was added water and surfactant, which was heated to $80^{\circ} \mathrm{C}$. The contents of the reaction flask containing the PLA and surfactant were rapidly poured into the flask containing the water and surfactant and allowed to stir for 1 hour. Samples PLA 16 - PLA 18: surfactant was

added to the reaction flask with rapid stirring and allowed to cool to $90{ }^{\circ} \mathrm{C}$. After one hour of stirring, water was added dropwise to the PLA and surfactant mixture. Then the flask was removed from the oil bath, cooled to room temperature, and allowed to sit overnight in the reaction flask. The resulting mixture was a two part mixture consisting of a top, aqueous layer, and a bottom, highly viscous polymer layer. The aqueous layer was poured into a bottle and films were attempted to be made from this formulation. The bottom polymer layer was removed from the flask by melting it, and was collected for later use. 
The details of each of these samples are given in Table 3.1.

\subsubsection{Solvent Switch Procedure for Samples PLA 14, 16, and}

\section{8}

The highly viscous, bottom polymer layers that were collected from the reaction vessels in the previously described procedure (3.2.2.1.2) were used to make dispersions utilizing a solvent-switch method. Three different surfactants were used to attempt to disperse the synthesized PLA. Using three of the polymer melts (PLA 14, containing Triton X-200, PLA 16, containing Triton X-100, and PLA 18, containing Surfynol 104H), each containing a different surfactant, the following procedure was employed: the polymer/surfactant mixture $(20 \mathrm{~g})$ was dissolved in dichloromethane $(30 \mathrm{~mL})$ in a 250 $\mathrm{mL}$ round bottom flask. After the polymer was fully dissolved, water $(16 \mathrm{~mL})$ was added to the flask and was generously swirled by hand. After the solutions were mixed, most of the dichloromethane was removed using a rotary evaporator. The solution was allowed to settle, and films were made using draw down bars. The details of each of these samples are given in Table 3.2.

\subsubsection{Second Hot Dispersion Procedure, Samples PLA 19 -}

\section{9}

Using the synthetic procedures outlined in section 2.2.2, PLA was synthesized in bulk. After a given amount of time for the reaction to proceed with the second initiator, a sample was removed for analysis and then surfactant and plasticizer were added to the reaction flask and allowed to stir for one hour at $90{ }^{\circ} \mathrm{C}$. After one hour of stirring, water was added dropwise to the PLA mixture. After stirring was complete, the flask was 
removed from the oil bath, allowed to cool to room temperature, and allowed to sit

overnight in the reaction flask. The resulting mixture was a two part mixture consisting of a top, aqueous layer, and a bottom, highly viscous polymer layer. The aqueous layer was poured into a bottle and films were attempted to be made from this solution. The bottom polymer layer was removed from the flask by melting it, and was collected for later use. The details of each of these samples are given in Table 3.3.

\subsubsection{Third Hot Dispersion Procedure, Samples PVA 1 - 4B}

The procedure for this method is similar to the procedure outlined in section 3.2.2.3 with several exceptions: 1) various hydrolyzed polyvinyl acetates were added to the PLA mixture at the same point as the surfactant and plasticizer, 2) for samples PVA $2-4 \mathrm{~B}$, heat was increased to $170{ }^{\circ} \mathrm{C}$ and refluxed with a condenser and reduced back to $90{ }^{\circ} \mathrm{C}$ after the addition of water, 3) solvent was added at the same point as water, 4) samples PVA 4 and PVA 4B contained some dissolved dispersing aid (type 1, $1.5 \mathrm{~g}$ per $100 \mathrm{~mL}$ of water) and lastly, 5) the polymer used for these samples was isolated and cooled after polymerization and reduced to a powder. A summary of these experiments is given in Tables 3.4 and 3.5 .

\subsubsection{Fourth Hot Dispersion Procedure, Samples PVA 4C33 -}

\section{A35}

The procedure for this section is exactly as detailed in 3.2.2.4, Third Hot Dispersion Technique, with the exception that a coalescing aid was added as the very last ingredient and that all the dispersing aid was added to the PLA melt. A summary of the ingredients for each sample can be seen in Table 3.6. A summary of the amount of coalescing aid for 
each sample can be seen in Table 3.7.

\subsubsection{Cold Dispersion Procedure, Samples PVA 8A36 - PVA}

\section{A38}

The procedure for the cold dispersion technique is, expectedly, largely similar to the procedure detailed in the previous Section (3.2.2.5). Using the synthetic procedures outlined in section 2.2.2, PLA was synthesized in bulk. After the polymerization was complete, the polymer was poured from the flask into a polystyrene cup (for ease of removal), and cooled to $0{ }^{\circ} \mathrm{C}$ in a freezer. After the polymer had cooled to $0{ }^{\circ} \mathrm{C}$, it was further cooled under liquid nitrogen and powderized using a high powered blender. Using both the blender and liquid nitrogen, the PLA was reduced to a very fine powder. The PLA powder, solvent, surfactant, plasticizer, and dispersing aid were placed into a 250 mL, 3-neck, round bottom flask. To the middle neck was attached a mechanical stirrer with Teflon coated stirrers. The other neck was sealed with a septum, and the remaining neck was left open for the addition of various ingredients. This mixture is allowed to stir rapidly until the ingredients are mostly homogeneous, about 2 hours, at room temperature. Water, dispersing aid, and solvent were placed into an addition funnel and added through the open neck of the flask dropwise. When successful, each drop added will result in a milky-white drop, indicating dispersion of the PLA. After the contents of the addition funnel have been added, the entire mixture is allowed to stir rapidly for 24 hours. After this time a coalescing aid is added to the mixture. A summary of the ingredients is given in Tables 3.8 and 3.9. 


\subsection{Results and Discussion}

\subsubsection{Hot Dispersion, Samples PLA 13 - PLA 18}

PLA samples 13 - 15 saw the rapid addition of hot molten PLA, which contained surfactant, to a cooler solution of water, which contained surfactant. None of these samples realized any success, defined as any dispersed solids in the aqueous phase. The cause of this is likely due to the rapid cooling of the PLA upon the addition of the molten PLA to water. The rapid cooling caused the polymer to aggregate to minimize its interaction with water. Once large particles of PLA had been formed, which likely contained surfactant trapped within the particles, dispersion would be impossible.

To counteract the rapid cooling of the PLA, samples PLA 16 - 18 used the addition of water in a dropwise manner. In these samples the temperature of the PLA solution was reduced to $90{ }^{\circ} \mathrm{C}$, only slightly below the boiling point of water. With the addition of water dropwise, the temperature in the reaction flask was maintained at $90{ }^{\circ} \mathrm{C}$ throughout the process. These samples also resulted in failure, as no solids were dispersed. The failure was simply attributed to the lack of micelle formation on the PLA and aggregation of the PLA. ${ }^{43}$ The resulting mixture of molten PLA and surfactant, although rapidly stirring and visually homogeneous, was likely a biphasic mixture with little interaction between the PLA and the surfactant. The molten PLA is extremely viscous, and very tacky, preferring interaction with itself over other substances in which it is insoluble. The details of these formulations are shown in Table 3.1. 
Table 3.1 Summary of the first attempts at hot dispersion, samples PLA 13 - PLA 18.

$\begin{array}{lccc}\text { Sample } & \begin{array}{c}\text { Solids } \\ \text { (wt\%) }\end{array} & \begin{array}{c}\text { Surfactant Type, Amount (wt\%) } \\ \text { In } \text { (nLA melt }\end{array} & \begin{array}{c}\text { Triton X-200, 2 (64) } \\ \text { In }\end{array} \\ \text { PLA 13 } & 32 & \text { Triton X-200, 2 } & \text { Triton X-200, 4 (61) } \\ \text { PLA 14 } & 31 & \text { Triton X-200, 4 } & \text { Triton X-200, 7 (57) } \\ \text { PLA 15 } & 29 & \text { Triton X-200, 7 } & \text { None (49, added dropwise) } \\ \text { PLA 16 } & 30 & \text { Triton X-200, 21 } & \text { None (49, added dropwise) } \\ \text { PLA 17 } & 30 & \text { Triton X-100, 21 } & \text { None (46, added dropwise) } \\ \text { PLA 18 } & 39 & \text { Surfonyl 104H, 15 } & \text { Solvent Switch, Samples PLA 14, 16, and 18 }\end{array}$

Since the failure of the previous PLA samples (PLA 13 - 18) were attributed to the failure of micelle formation, a method was designed to assist in micelle formation.

Because the hot dispersion method always had the PLA in a molten, semi-fluid state, it was never in solution, so the probability of micelle formation was very small. Since the surfactants used are in an aqueous environment and the PLA is in a molten state, any interactions between the two phases are difficult just by virtue of being in different phases.

The hypothesis of the solvent switch method was to utilize PLA which already had surfactant entrapped within its mass and dissolving the mass into a solvent in which PLA is soluble. PLA is very soluble in dichloromethane, so this solvent was chosen for this procedure. PLA is soluble in dichloromethane, thus using this procedure the PLA would be dissolved in the liquid phase, and would more favorably interact with the water phase (although dichloromethane and water are immiscible). Nearly all of the surfactant will be in the aqueous phase. When the entire mixture is then placed on the rotary evaporator, the dichloromethane will be removed first, causing the PLA to reach its solubility limit at a certain concentration. At this point the PLA will be forced to either precipitate out of solution or, ideally, become encased in a surfactant micelle and form an dispersion. 
What was observed in all three cases was an opaque liquid layer and a mass of semi-solid PLA at the bottom of the flask. The liquid layer was removed and then draw downs were made from the fluid to test for dispersed solids. In all three cases, solids were observed after the liquid had dried from the drawdown. However, this is likely not attributed to the PLA having been dispersed. What likely occurred was that there was residual solvent, and thus dissolved PLA in the liquid mixture. Given several hours all, three solutions were observed to settle into distinct layers of solid, and two liquid layers, corresponding to water and residual solvent. The details of these formulations are shown in Table 3.2.

Table 3.2 Summary of the attempts at the solvent switch method, samples PLA 14, 16, 18

\begin{tabular}{|c|c|c|c|c|c|c|c|}
\hline \multirow{2}{*}{ Sample } & \multirow{2}{*}{\multicolumn{2}{|c|}{$\begin{array}{l}\text { Solids (g) } \\
\text { (g) } \quad \text { (wt\%) }\end{array}$}} & \multirow{2}{*}{ Surfactant } & \multirow{2}{*}{\multicolumn{2}{|c|}{$\begin{array}{l}\text { Solvent (mL) } \\
\text { (q) }\end{array}$}} & \multicolumn{2}{|c|}{ Water $(\mathrm{mL})$} \\
\hline & & & & & & (g) & (wt \%) \\
\hline PLA 14 & 20 & 30 & Triton X-200 & 30 & 45 & 16 & 25 \\
\hline PLA 16 & 20 & 30 & Triton X-100 & 30 & 45 & 16 & 25 \\
\hline PLA 18 & 20 & 30 & Surfynol $104 \mathrm{H}$ & 30 & 45 & 16 & 25 \\
\hline
\end{tabular}

\subsubsection{Second Hot Dispersion of Samples PLA 19 - 29}

The method utilized here realized various levels of success. An understanding of what each ingredient, given in Table 3.3, contributed to the overall dispersion of the polymer was the key for this portion of the study. Increasing the amount of plasticizer in the mixture allowed for more dispersed solids, but significantly reduced the overall properties of the final polymer film. When too much plasticizer was used, generally above 5 weight percent, the final film was tacky and unsuitable for use. Increasing surfactant had similar results in that the more surfactant was used more dispersed solids would be the result. However, the effect of additional surfactant was less dramatic than with increased plasticizer. At this portion of the project testing of the characteristics of the 
films were not being conducted yet, but it would be later discovered that additional surfactant, while not resulting in a significant decrease in the properties of the film, did significantly reduce the coating's water resistance. For this portion of the study however, the primary objective was to maximize dispersed solids any way possible. Amount of water seemed only to have the effect of diluting the resulting mixture and seemed to be largely independent of the final dispersed solids of the mixture. Additional water had an adverse affect on the film formation of the mixture. However, by adding more water to the mixture the final viscosity of the liquid was reduced which hindered the film's ability to coalesce. A more viscous formulation was found to coalesce better, simple due to the increase in solids content. The details of these formulations are shown in Table 3.3.

Table 3.3 Summary of the various experiments for the second hot dispersion technique.

\begin{tabular}{|c|c|c|c|c|c|c|c|c|}
\hline \multirow[b]{2}{*}{ Sample } & \multicolumn{2}{|c|}{ Solids } & \multicolumn{2}{|c|}{ Plasticizer } & \multicolumn{2}{|c|}{ Surfactant $^{a}$} & \multicolumn{2}{|c|}{ Water } \\
\hline & (g) & (wt \%) & (g) & (wt\%) & (g) & (wt\%) & (g) & (wt\%) \\
\hline PLA 19 & 25 & 29.5 & 3.2 & 3.8 & 18.6 & 21.9 & 38 & 44.8 \\
\hline PLA 20 & 25 & 29.5 & 3.2 & 3.8 & 18.5 & 21.8 & 38 & 44.9 \\
\hline PLA 21 & 25 & 26.8 & 3.4 & 3.6 & 30 & 32.1 & 35 & 37.5 \\
\hline PLA 23 & 25 & 17.4 & 5.05 & 3.5 & 23.9 & 16.6 & 90 & 62.5 \\
\hline PLA 24 & 50 & 28.7 & 5.25 & 3.0 & 28.7 & 16.5 & 90 & 51.7 \\
\hline PLA 25 & 50 & 28.4 & 5 & 2.8 & 31.3 & 17.8 & 90 & 51.0 \\
\hline PLA 26 & 50 & 28.4 & 5.66 & 3.2 & 30.4 & 17.3 & 90 & 51.1 \\
\hline PLA 27 & 50 & 27.5 & 10.75 & 5.9 & 31.1 & 17.1 & 90 & 49.5 \\
\hline PLA 28 & 50 & 18.6 & 29.4 & 10.9 & 68.5 & 25.5 & 121 & 45.0 \\
\hline PLA $29^{a}$ & 25 & 23.3 & 4.7 & 4.4 & 27.5 & 25.7 & 50 & 46.6 \\
\hline
\end{tabular}
All plasticizers used are Hexamoll, all surfactants used are Triton X-200, unless otherwise noted. Weight percents are given for the total ingredients added to the mixture, not the resulting liquid, which in all cases did not contain all solids initially added. ${ }^{a}$ surfactant: DABCO DC 5598.

\subsubsection{Choice of Plasticizer}

The plasticizer, Hexamoll, was chosen based on PLA's solubility in three different plasticizers supplied by the sponsor of this study. The other two plasticizers supplied 
were Palatinol and Plastamol. All three are manufactured by BASF. The structure of Hexamoll is shown in Figure 3.2.

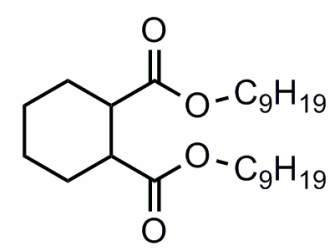

Figure 3.2 Structure of Hexamoll.

\subsubsection{Choice of Surfactant}

In addition, the remainder of this study would be carried out using Triton X-200 as the surfactant. This was chosen based on film formation and solids content from previous experiements. The structure of Triton X-200 is shown in Figure 3.3.

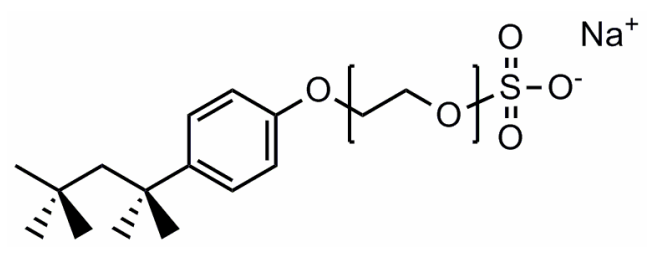

Figure 3.3 Structure of Triton X-200.

\subsubsection{Third Hot Dispersion, Samples PVA 1 - 4B}

Since the purpose of this study is to develop a biodegradable coating for paper packages, an implicit objective is to develop a coating that could be described as 'sustainable' or 'green.' While an attempt was made to avoid the use of organic solvents, at this point in the study it was deemed necessary to proceed. Acetone was the solvent of choice for all successive experiments. Acetone was a natural choice as an organic solvent for this study. First and foremost, PLA is very soluble in acetone; in addition, it is easy to use and readily available. However, acetone was also chosen because it is considered 
exempt from the Environmental Protection Agency's list of volatile organic compounds (VOCs). ${ }^{44}$ The EPA has decided to exclude acetone as a VOC "on the basis that acetone has been determined to have negligible photochemical reactivity." This factor was a significant contributor to acetone being chosen as the solvent used in this study.

The use of acetone in the coating formulation finally gave the resulting liquid coatings an appreciable amount of solids, and drawdowns of fully coalesced films could be made for the first time. The acetone greatly helped solubilize the PLA as well as the dispersing aid, which in turn, allowed for significant interaction with the surfactant. In addition, acetone is miscible with water, which allowed for easier micelle formation. Since there was not enough acetone present to fully dissolve all the PLA, when the mixture contained water, solvent, PLA, and surfactant, these could all exist in the same phase and micelles were created, thus dispersing the PLA.

Using hydrolyzed polyvinyl acetate, essentially polyvinyl alcohol (PVA), as an dispersing aid allowed for much more dispersion of PLA, as the resulting liquid contained more dispersed solids. Since hydrolyzed PVA is water soluble, yet of similar structure to PLA, shown in Figure 3.4, it can act as an dispersing aid in a different way than the Triton X-200 surfactant. The PVA chains will interact with the PLA chains in the form of hydrogen bonding, shown in Figure 3.5. Since the PVA chains are water soluble, if the PLA chains are bonded to them, then the PLA will have a much higher affinity for water than the PLA itself. It should be noted, however, that hydrolyzed PVA begins to lose its solubility in water if it is hydrolyzed to a high extent. The intermolecular hydrogen bonding will be too great to overcome and it will actually be insoluble in water, 
in a similar fashion to cellulose.<smiles>CCC(CC(C)(C)C)OC(C)=O</smiles>

Polyvinyl acetate<smiles>CCC(O)C(C)(C)C(C)(C)C</smiles>

Polyvinyl alcohol<smiles>COC(=O)C(C)C</smiles>

Polylactic acid

Figure 3.4 Strutures of polyvinyl acetate, polyvinyl alcohol, and polylactic acid.

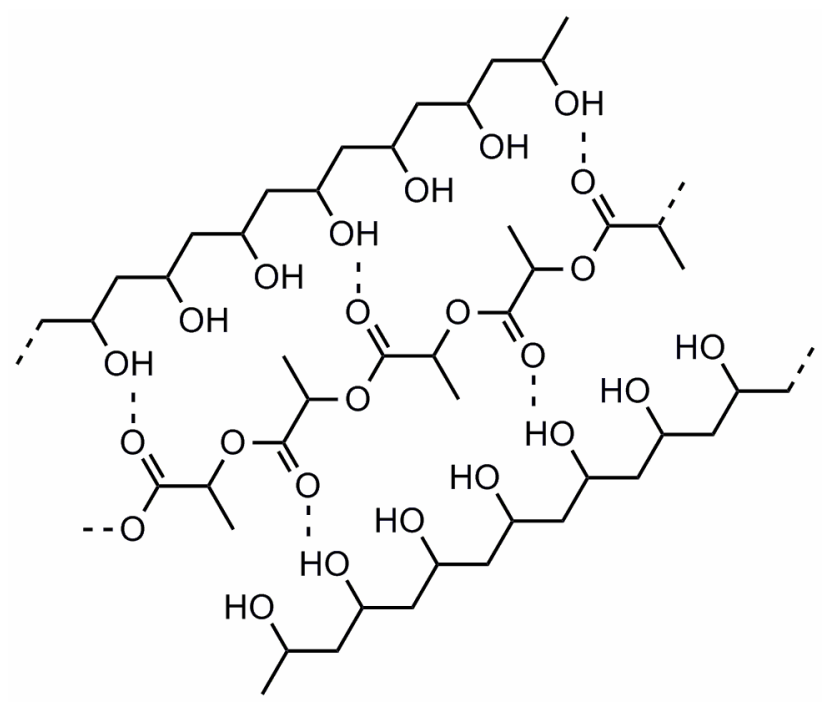

Figure 3.5 Schematic of the method of action for dispersing aid, polyvinyl alcohol with PLA.

In addition to using solvent in this portion of the study to help improve the coating formulation, the effect of the various types of PVA was examined. Three different types of hydrolyzed polyvinyl acetates were used in this section of the study, which will be called PVA type 1, 2 and 3. The dispersing agents by type: 1, polyvinyl acetate, 99\% hydrolyzed, 31-50k g/mol; 2, polyvinyl acetate, $75 \%$ hydrolyzed, 3k g/mol; 3, polyvinyl acetate, $100 \%$ hydrolyzed, $14 \mathrm{k} \mathrm{g} / \mathrm{mol}$. It was found that type 2 was the most effective at dispersing the PLA. The reason for this is that this type of hydrolyzed PVA used was only partially hydrolyzed at $75 \%$, compared to $99 \%$ and $100 \%$ for types 1 and 3, respectively. 
While having more alcohol functional groups along the polymer's backbone will cause the polymer to be more water soluble, having some of the polymer backbone maintain its acetate groups will cause the PVA to interact more favorably with PLA. The acetate group on PVA closely mirrors the functionality of PLA. While having a lower portion of hydrolyzed groups will result in less hydrogen bonding, this type of PVA allows for more favorable Van der Waals than either of the other types of PVAs used, yet still allows for hydrogen bonding.

Another important step for this section of the study was the use of powdered PLA. After the polymerizations were complete, the molten PLA was cooled to room temperature and ground into a powder using a mortar and pestle. Previous attempts at adding ingredients to a molten PLA likely caused particle sizes that were too large for dispersion and more importantly, allowed for the PLA to remain as one mass for the duration of the experiment. By using powdered PLA there was much more surface area present per given mass of the polymer, which allowed more interaction with the ingredients.

Lastly, the use of water containing some dissolved PVA was explored. This would turn out to be a key factor in this study, and would not be explored again until the use of the technique detailed in Section 3.3.6, Cold Dispersion, Samples PVA 8A36 - PVA 8A38.

With the addition of solvent and the use of powdered PLA a much higher amount of solids in the final coating formulation was realized. It was hypothesized that the order of addition of the various ingredients was likely to be of paramount importance. The details 
of the formulations of these samples are shown in Tables 3.4 and 3.5.

Table 3.4 Summary of experiments performed in Third Hot Dispersion Procedure.

\begin{tabular}{|c|c|c|c|c|c|c|c|c|}
\hline \multirow[b]{2}{*}{$\begin{array}{c}\text { Sample } \\
\text { (polymer used) }\end{array}$} & \multicolumn{2}{|c|}{ Solids } & \multicolumn{2}{|c|}{ Water } & \multicolumn{2}{|c|}{$\begin{array}{c}\text { Dispersing } \\
\text { Agent }\end{array}$} & \multirow{2}{*}{$\begin{array}{l}\text { Plasticizer } \\
\text { (wt\%) }\end{array}$} & \multirow{2}{*}{$\begin{array}{l}\text { Surfactan } \\
\text { (wt\%) }\end{array}$} \\
\hline & (g) & (wt \%) & (g) & (wt\%) & Type $^{\text {a }}$ & (wt\%) & & \\
\hline PVA 1 (PLA 30) & 20 & 30.4 & 41 & 62.3 & 1 & 2 & 4.3 & 0.0 \\
\hline PVA 2 (PLA 31) & 20 & 26.7 & 28.7 & 38.4 & 2,3 & 3.4 & 1.3 & 5.5 \\
\hline PVA 3 (PLA 31) & 20 & 31.2 & 29 & 45.3 & 4 & 4 & 2.0 & 0.0 \\
\hline PVA 4 (PLA 31) & 20 & 27.7 & 25 & 34.6 & 3 & 5.2 & 3.1 & 11.1 \\
\hline PVA 4B (PLA 32) & 72 & 28.6 & 90 & 35.7 & 2 & 7.4 & 3.2 & 11.6 \\
\hline $\begin{array}{l}\text { Total mass in grams } \\
\text { Plasticizer was Hexc } \\
\text { hydrolyzed, } 31-50 k\end{array}$ & $o l ;$ & $\begin{array}{l}\text { for bot } \\
\text { factant } \\
\text { polyviny }\end{array}$ & PLA s & $\begin{array}{l}\text { ids and } \\
X-200 . \\
75 \% \text { hy }\end{array}$ & $\begin{array}{l}\text { ater to } \\
\text { dispersi } \\
\text { olyzed, }\end{array}$ & a scope & $\begin{array}{l}\text { the scale of } t \\
\text { olyvinyl acet }\end{array}$ & $\begin{array}{l}\text { experiment. } \\
\text { e, } 99 \% \\
100 \%\end{array}$ \\
\hline
\end{tabular}

Table 3.5 Summary of weight percent solvent (acetone) added to samples PVA 2 - 4B.

$\begin{array}{cr}\text { Sample (polymer used) } & \text { Solvent ( } \\ \text { PVA 2 (PLA 31) } & 23.5 \\ \text { PVA 3 (PLA 31) } & 15.2 \\ \text { PVA 4 (PLA 31) } & 16.4 \\ \text { PVA 4B (PLA 32) } & 13.5\end{array}$

\subsubsection{Fourth Hot Dispersion, Samples PVA 4C33 - 7A35}

These samples saw largely the same amount of success as the previous section's (3.3.4) except that films which were drawn down showed a higher amount of coalescence and better film formation because of the addition of coalescing aid, Texanol, to the formulation. Details of the formulations are shown in Table 3.6. 
Table 3.6 Summary of the ingredients in samples PVA 4C33 - PVA 7A35.

\begin{tabular}{|c|c|c|c|c|c|c|}
\hline $\begin{array}{c}\text { Sample } \\
\text { (polymer } \\
\text { used) }\end{array}$ & $\begin{array}{l}\text { Solids } \\
\text { (wt \%) }\end{array}$ & $\begin{array}{l}\text { Water } \\
\text { (wt\%) }\end{array}$ & $\begin{array}{c}\text { Dispersing Agent }{ }^{\mathrm{a}} \\
(w t \%)\end{array}$ & $\begin{array}{l}\text { Plasticizer } \\
\text { (wt\%) }\end{array}$ & $\begin{array}{c}\text { Surfactant } \\
\text { (wt\%) }\end{array}$ & $\begin{array}{l}\text { Coalescing } \\
\text { Aid } \\
\text { (wt\%) }\end{array}$ \\
\hline $\begin{array}{l}\text { PVA 4C33 } \\
\text { (PLA 33) }\end{array}$ & 27.0 & 33.8 & 7.0 & 3.1 & 10.9 & 2.2 \\
\hline $\begin{array}{l}\text { PVA 4D34 } \\
\text { (PLA 34) }\end{array}$ & 26.9 & 33.6 & 7.0 & 3.1 & 10.9 & 2.5 \\
\hline $\begin{array}{l}\text { PVA 5A35 } \\
\text { (PLA 35) }\end{array}$ & 28.5 & 35.5 & 7.4 & 3.3 & 5.8 & 2.6 \\
\hline $\begin{array}{l}\text { PVA 6A35 } \\
\text { (PLA 35) }\end{array}$ & 22.3 & 42.0 & 5.8 & 2.6 & 4.6 & 3.0 \\
\hline $\begin{array}{l}\text { PVA 7A35 } \\
\text { (PLA 35) }\end{array}$ & 11.6 & 69.8 & 3.0 & 1.3 & 2.4 & 1.6 \\
\hline
\end{tabular}

\subsubsection{Cold Dispersion, Samples PVA 8A36 - PVA 8A38}

This technique was the most successful of all the methods utilized. Although the ingredients are the same as in the previous section (3.3.5), this method was much more successful. Obviously, heat causes less PLA to be dispersed. One simple explanation for this is that at elevated temperatures solubility limits are increased. If the sample is heated to high temperatures, higher concentrations of components may dissolve at these high temperatures, but when the formulation is cooled to room temperature these components may precipitate from solution.

In these samples, the key factor leading the micellization of the PLA particles is the hypothesis that many of the micelles are already formed in the water solution and are essentially 'empty.' This phenomenon has been observed with dioctyl sodium sulfosuccinate. ${ }^{45}$ With the addition of the water mixture to the PLA mixture, the particles become micellized and are then dispersed, as depicted in Figure 3.6. It has been reported 
that carboxy-terminated polybutadiene has been micellized in PVA. ${ }^{46}$

Table 3.7 Summary of Samples PVA 8A36 - PVA 8A38.

$\begin{array}{cccc}\text { Sample } & \text { Polymer } & \text { Dispersing Aid }\left(\text { Type }^{\text {a) }}\right) & \text { Coalescent (wt\%) } \\ \text { PVA 8A36 } & \text { PLA 36 } & 2 & 2.1 \\ \text { PVA 8B36 } & \text { PLA 36 } & 4 & 1.9 \\ \text { PVA 8C36 } & \text { PLA 36 } & 5 & 1.9 \\ \text { PVA 8A37 } & \text { PLA 37 } & 2 & 2.1 \\ \text { PVA 8A38 } & \text { PLA 38 } & 2 & 2.1\end{array}$

Surfactant, Triton X-200 (3.1\%); solvent, acetone (13.4\%); coalescent, Texanol; plasticizer, Hexanol (1.8\%); polymer $(15.1 \%) .75 \%$ of the listed amount of solvent and dispersing aid were placed into the flask containing the powdered PLA, the remaining $25 \%$ were dissolved in the water prior to addition. ${ }^{a}$ The dispersing aid varied: type 2, polyvinyl acetate. $75 \%$ hydrolyzed, $3 \mathrm{~kg} / \mathrm{mol} ; 4$. polyethylene glycol, 600 $\mathrm{g} / \mathrm{mol} ; 5$, polyethylene glycol, $1.5 \mathrm{~kg} / \mathrm{mol}$.

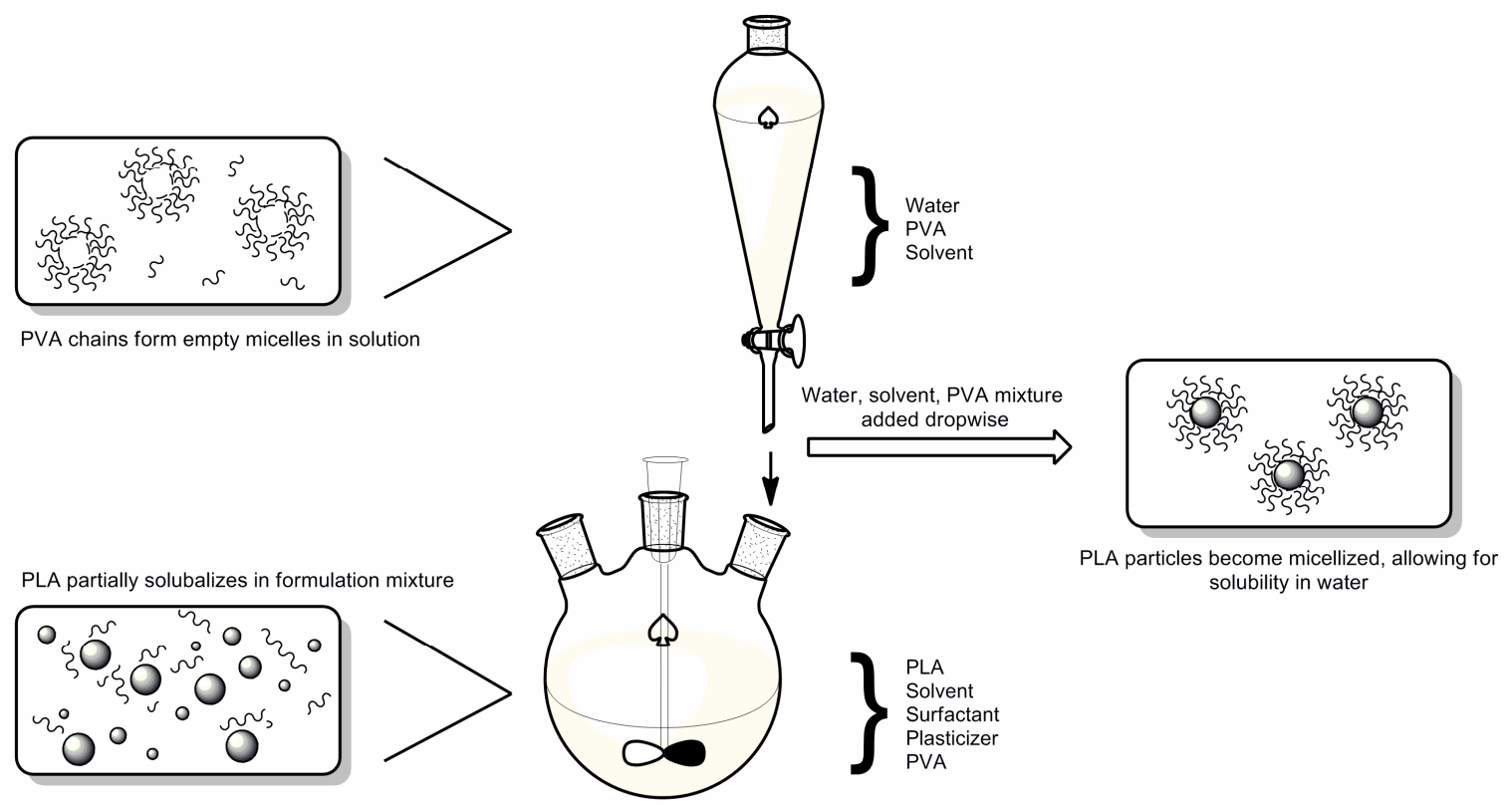

Figure 3.6 Schematic of dispersion of PLA particles.

All five of the samples in this section are largely similar in their composition.

Samples PVA 8A36, PVA 8B36 and PVA 8C36 are all identical except for the type of dispersing aid used. It was hypothesized that perhaps polyethylene glycol may act as an improved dispersing aid over the partially hydrolyzed PVA that had been used. This 
hypothesis was found to be incorrect, as the partially hydrolyzed PVA was found to perform much better than either sample with the PEG.

Samples PVA 8A36, PVA 8A37, and PVA 8A38 only varied in that they contained different polymer, as shown in Tables 3.7 and 3.8. PVA 8A36 contained polymer PLA 36, PVA 8 A37 contained polymer PLA 37, and PV88A38 contained polymer PLA 38. The best performing sample in this section was PVA 8A37, which corresponds accordingly with its molecular weight and MWD. PLA 37 has the lowest molecular weight of the three polymers used, and also has the largest MWD. This can be seen in the GPC trace in Figure 3.7, shown as the blue curve, which has the most bimodal distribution of the three polymers.

Table 3.8 Summary of the polymers used in samples PVA 8A36, PVA 8A37, and PVA $8 \mathrm{~A} 38$.

$\begin{array}{cccc}\text { Sample } & \text { Polymer } & \text { Molecular Weight }(\mathbf{g} / \mathbf{m o l}) & \text { PDI } \\ \text { PVA 8A36 } & \text { PLA 36 } & 7,000 & 1.24 \\ \text { PVA 8A37 } & \text { PLA 37 } & 6,000 & 1.40 \\ \text { PVA 8A38 } & \text { PLA 38 } & 6,700 & 1.27\end{array}$




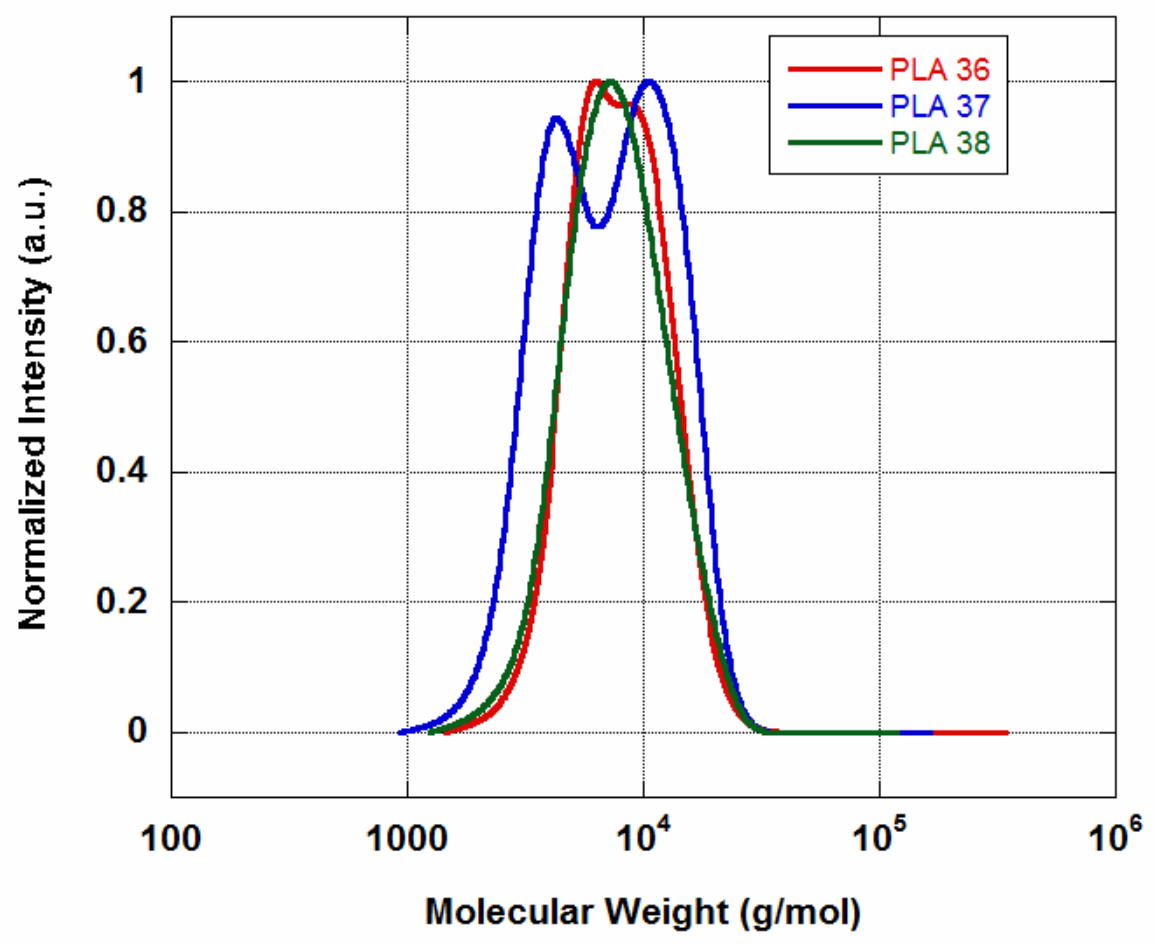

Figure 3.7: GPC analysis of polymers PLA 36, 37 and 38.

The amount of solids in the resulting coating formulation was generally increased with increasing PDI of the polymer. Additionally, lower molecular weight generally resulted in increased dispersed solids, but tends to lower overall performance of the resulting film if molecular weight is too low $(\sim 2,000 \mathrm{~g} / \mathrm{mol}$ or less $)$. It should also be noted that the samples in this section were the only ones listed for any of the samples in Chapter 3, Coatings Formulation, whose resulting coating formulation contained the entire portion of solids listed in their respective tables. Table 3.9 shows the formulation of the most successful composition. 
Table 3.9 Final formulation of polylactic acid waterborne coating.

\begin{tabular}{cccc} 
Ingredient & PVA 8A37 & \multicolumn{2}{c}{ Amount added } \\
Polylactic Acid (PLA 37) & Function & (g) & (wt\%) \\
Water & Resin & 25 & 15.1 \\
Acetone & Vehicle & 100 & 60.6 \\
Polyvinyl acetate, 75\% & Solvent & 22.1 & 13.4 \\
hydrolyzed, 3k g/mol & Dispersing Aid & 6.5 & 3.9 \\
Triton X-200 & Surfactant & 5.1 & 3.1 \\
Texanol & Coalescing Aid & 3.4 & 2.1 \\
Hexamoll & Plasticizer & 2.9 & 1.8
\end{tabular}

\subsubsection{Attempts at Scale Up of PVA 8A37}

Attempts were made to scale up the formulation of PVA 8 A37 to larger scales. As it was developed, as shown in Table 3.9, 25 grams of resin were used. Attempts using the exact same ratios of ingredients and procedures did not yield similar results. At scales above 25 grams of polymer the result is a viscous solid bottom layer of polymer and an aqueous top layer with little dispersed solids. The reasons for this are largely unclear, but failure may be due to reduced shear in the flask (the same stirrer and blades were used for scale up), or simply be due to diffusion problems on a larger scale.

\subsection{Coating Application and Testing}

During the coating formulation portion of this study only 4 mil drawdowns were prepared to test the film forming ability of the coatings. This was sufficient to demonstrate whether or not the resulting formulation would adequately form a film. Since one of the objectives of the project was to deliver a coating that could be spray applied, once a formulation was developed that was deemed adequate (PVA 8A37), all subsequent testing was conducted by spray application and with sample PVA 8A37. However, grease resistance testing was conducted with 4 mil drawdowns to compare the 
two application methods.

The benefits of spray applying a coating are that it allows for full coverage on difficult to coat that are shaped awkwardly. For example, rather than laminating a piece of paperboard then folding it into its desired shape, a spray methods allows for full coverage of the folded paperboard after it has been shaped. Spray applying coatings is also very quick and can allow for very thin films to be deposited. In addition it can allow for more complete coverage of a package compared to lamination. With a spray application method seams and corners can be fully covered, which can allow for improved grease resistance of the resulting package as shown in Figure 3.8.
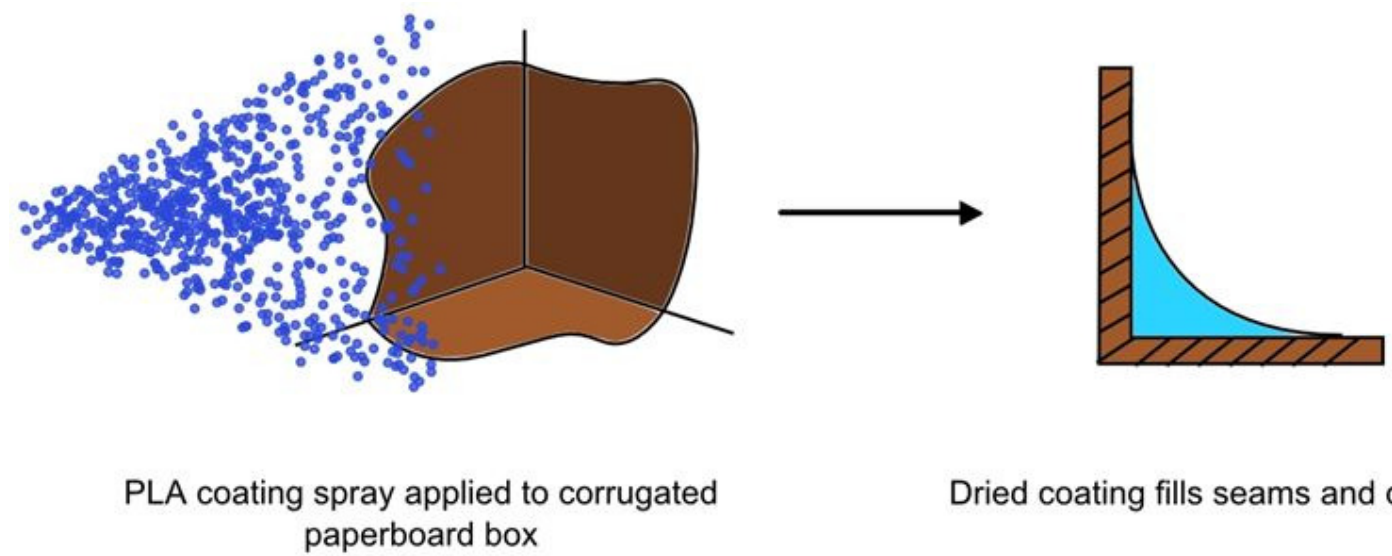

Figure 3.8 Schematic illustrating the benefits of spray application of coatings.

\subsubsection{Spray Application}

An objective for this project was to deliver a coating formulation which could be spray applied.

\subsubsection{Spray Procedure}

A gel coat dump gun was loaded with sample and equipped with either a 1/16" or $1 / 32$ " nozzle and attached to an in-house pressurized air line. For the $1 / 16$ " nozzle a spray 
time of 10 seconds was used, for the 1/32" nozzle a spray time of 20 seconds was used. The nozzle of the gun was held perpendicular to a piece of corrugated paperboard oriented at a $45^{\circ}$ angle and sprayed uniformly by hand over a 4 " by 4" area. The coated corrugated paperboard pieces are then placed in an oven at $50{ }^{\circ} \mathrm{C}$ for 5 minutes, and then are let dry for 1 hour at room temperature prior to any testing. The average coat weight and thickness are given in Table 3.10.

Table 3.10 Summary of average coat weight for spray applied coatings.

\begin{tabular}{|c|c|c|}
\hline & \multicolumn{2}{|c|}{ Nozzle size (in.) } \\
\hline & $1 / 32$ & $1 / 16$ \\
\hline Coat Weight $\left(\mathrm{mg} / \mathrm{in}^{2}\right)$ & 6.33 & 17.55 \\
\hline Coat Thickness (mil) & 1.32 & 1.83 \\
\hline
\end{tabular}

\subsubsection{Coating Testing Procedure}

The coatings were tested for their grease resistance in accordance with TAPPI 559 (ASTM D722). Anhydrous calcium chloride (5 g) and oil soluble red dye (1.0 g) were added to turpentine $(100 \mathrm{~mL})$. The container is shaken well and let stand for 10 hours, and is then filtered with dry filter paper and stored in an airtight container. The test specimens for this procedure were the coated corrugated paperboard samples supplied by the sponsors of this study. A sheet of plain white paper is placed on the bench top and the test specimen is placed directly on top of this piece of paper. A 1 inch tube (about 4 inches long) is placed on the center of the test specimen and filled with 5 grams of Ottawa sand (20-30 sieve). The tube is lifted as to evenly distribute the sand into a pile on top of the test specimen. To the pile of sand is pipetted $1.1 \mathrm{~mL}$ of dyed turpentine. As soon as the turpentine is deposited, a timer is started. Every ten seconds the test specimen 
is lifted to determine if any of the dyed turpentine has reached the white paper

underneath. The test is concluded and the timer stopped when any sign of color is seen on the white paper, or when 1800 seconds have elapsed.

\subsubsection{Results and Discussion}

Testing was conducted on specimens that were coated by spray application with both $1 / 16$ " and 1/32" nozzles, 4 mil drawdowns, and uncoated specimens. The results of the tests are shown in Table 3.11. All coated samples resisted penetration of the grease for the duration of the time stipulated by ASTM D722 (1800s). The test was unofficially continued for these samples and it was found that grease soaked through the three samples after approximately 1 hour. For the uncoated sample, grease soaked through after 50 seconds. This test demonstrates both that the coating prepared in this study is an adequate grease barrier, and that spray application of the coating is a suitable method of application. Figure 3.9 shows images of the grease testing for spray applied coatings $(1 / 16 ")$ and for uncoated samples. It is observed that after 1800 s the coated sample shows no grease penetration, but for the uncoated sample after approximately two minutes grease has readily penetrated the entirety of the paperboard.

Table 3.11 Results of grease resistance testing.

\section{Sample} Uncoated

Spray applied, 1/16"

Spray applied, 1/32"

4 mil drawdown
Elapsed Time at Failure (s)

50

$>1800$

$>1800$

$>1800$ 


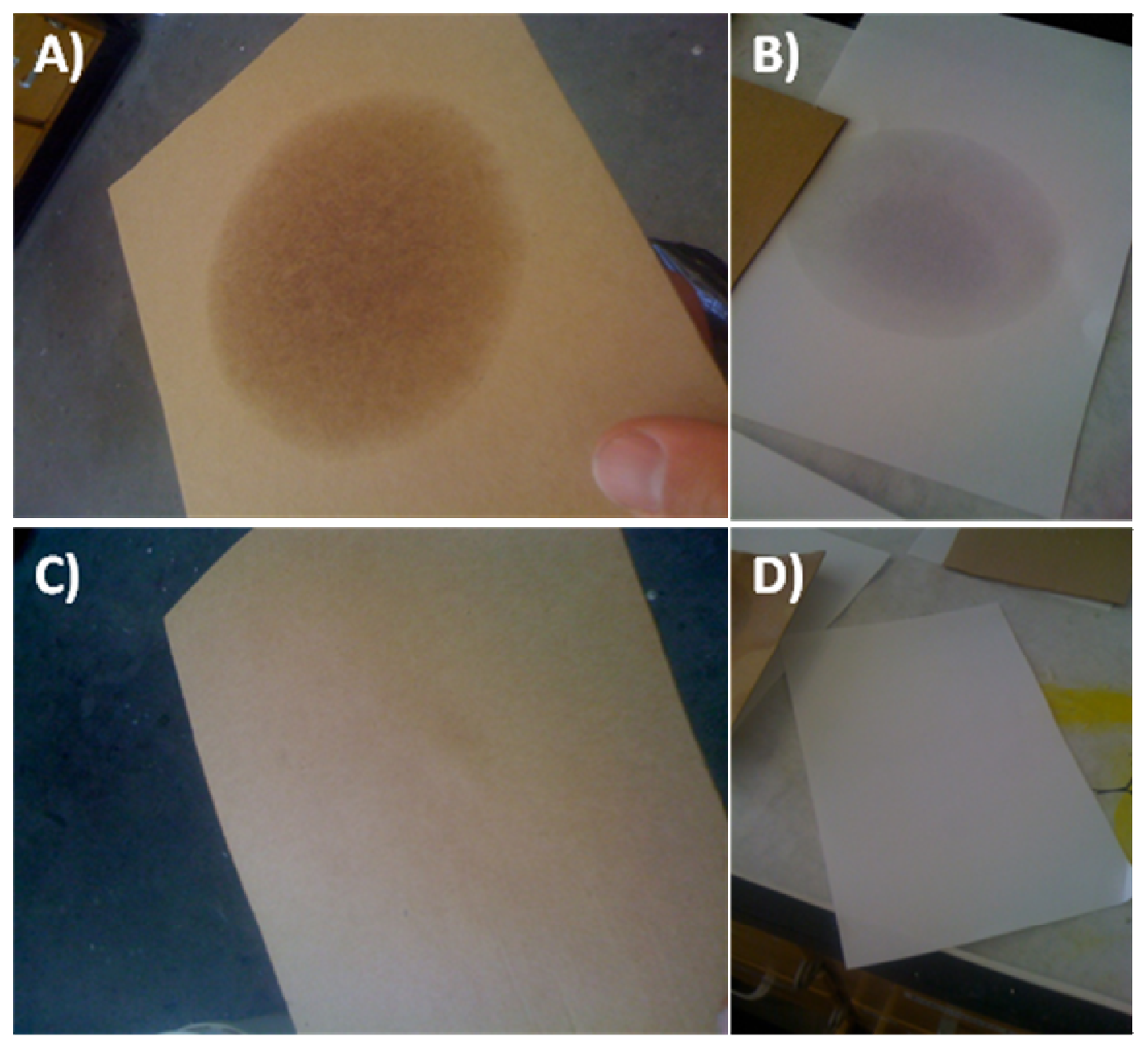

Figure 3.9 Grease resistance testing for uncoated (images A and B) and coated (images C and D) samples in accordance with ASTM D722. A) Underside of uncoated sample. B) Test paper underneath uncoated sample. C) Underside of coated sample. Grease was found to not soak through to the underside in any duration of time. D) Test paper underneath coated sample.

\subsection{Conclusions}

PLA was successfully dispersed and formulated into a waterborne coating for use as a grease barrier for paper packaging. Using a cold dispersion technique, a formulation with 15 weight percent PLA was achieved. It was determined that the components and order of addition was critical to the success of the formulations. Each ingredient used had its own purpose and allowed for a more successful formulation. Perhaps most critical to the 
success of the formulations was the order of addition of each ingredient. It was found that adding the ingredients in a fashion which allowed for micelle formation in water prior to addition to PLA which had been solubilized in various other ingredients was the most successful method. The most successful formulation mixed water, PVA, and solvent in part A, PLA, solvent, surfactant, plasticizer, and PVA in part B, then part A was added dropwise to part B. This coating was successfully spray applied and performed well as a grease barrier, resisting grease for the maximum allotted time under ASTM D722. 


\section{Hot Melt Adhesive}

\subsection{Concept}

A secondary objective of this study was to develop a biodegradable hot melt adhesive from polylactic acid. Narrow molecular weight distribution, or monodispersed, high molecular weight resins of PLA were formulated for their use as hot melt adhesives. PLAs 1, and 6-12 were synthesized for use as hot melt adhesives. The samples synthesized for use as the hot melt adhesive ranged in molecular weight from about 5,000 $\mathrm{g} / \mathrm{mol}$ up to over $45,000 \mathrm{~g} / \mathrm{mol}$. All the resins were prepared via solution polymerization, which after precipitation into cold hexanes, had a large amount of residual solvent trapped within the polymer matrix. All resins showed great potential for use as a hot melt adhesive, since all the samples were extremely tacky. Prior to drying in the oven, the samples contained residual solvent, which acted as a plasticizer, resulting in samples that were very sticky. However, after drying the samples in the oven at $70^{\circ} \mathrm{C}$ for one week, nearly all the residual solvent was removed from the samples, and the resulting resins were either flexible or brittle, but not sticky. The amount of solvent, or plasticizer, present in the resins seems to directly correlate to how tacky the resins are. The tacky resins stick well to nearly all substrates they come in contact with, from glass, to steel, to paperboard, and skin.

The greatest adhesive strength occurred when a lower molecular weight resin was blended with a higher molecular weight resin. Lower molecular weight resins appear to allow for greater interdigitation of the polymer chains than do high molecular weight resins. However, due to the lower yield strength of lower molecular weight PLA, it is 
important to blend higher molecular weight PLA into the hot melt formulation to provide the necessary strength.

\subsection{Experimental}

\subsubsection{Materials}

Corrugated paperboard and paperboard were supplied by the sponsors of this study. A TA Instruments Q-Series DSC was used to perform differential scanning calorimetry analysis on the samples. A TA Instruments Q-Series TGA was used to perform thermal gravimetric analysis on the samples. An Agilent 1200 RI liquid chromatograph using PSS WinGPC Unity software was used to perform gel permeation chromatography on the samples.

\subsubsection{Methods}

Samples were tested using differential scanning calorimetry (DSC) and thermal gravimetric analysis (TGA).

\subsubsection{Differential Scanning Calorimetry (DSC) Method}

All samples tested on the DSC used the following method. PLA samples between 3 and 10 milligrams were weighed into aluminum hermetic pans. A nitrogen flow rate of $50.0 \mathrm{~mL} / \mathrm{min}$ was used. The sample was equilibrated at $0{ }^{\circ} \mathrm{C}$, ramped at $5.00{ }^{\circ} \mathrm{C} / \mathrm{min}$ to $200.00{ }^{\circ} \mathrm{C}$, ramped at $5.00{ }^{\circ} \mathrm{C} / \mathrm{min}$ to $0.00{ }^{\circ} \mathrm{C}$, then ramped at $5.00{ }^{\circ} \mathrm{C} / \mathrm{min}$ to $200{ }^{\circ} \mathrm{C}$.

\subsubsection{Thermal Gravimetric Analysis (TGA) Method}

All samples tested on the TGA used the following method. PLA samples between 5 and 20 milligrams were weighed into aluminum pans. A nitrogen balance gas flow of $40.0 \mathrm{~mL} / \mathrm{min}$, and a sample gas flow of $60.0 \mathrm{~mL} / \mathrm{min}$ was used. The sample was heated at 
a rate of $20.00{ }^{\circ} \mathrm{C} / \mathrm{min}$ to $500{ }^{\circ} \mathrm{C}$.

\subsubsection{Hot Melt Adhesive Preparation Procedure}

Low molecular weight polymer ( 1 g, ex. PLA 7) and high molecular weight polymer $(\sim 1 \mathrm{~g}$, ex. PLA 12) were placed in a vial and heated until molten, at which point they were mixed by hand using a spatula. Using paperboard supplied by the sponsor of the study a droplet, about the size of the end of the spatula, $\sim 0.1 \mathrm{~g}$, was placed on one piece

of the paperboard. Another piece of paperboard was quickly placed on top of the drop and the two pieces were pressed together by hand. After the hot melt had cooled to room temperature $(\sim 5 \mathrm{~min})$, a peel test was performed.

\subsection{Results and Discussion}

\subsubsection{Results of Peel Test}

For many different combinations of PLA mixtures a crude peel test (sample was pulled from substrate by hand), resulted in substrate failure (the paperboard debonded from itself), leading to the conclusion that an adequate hot melt had been developed. Various substrates were tested including corrugated paperboard, and glossy and nonglossy paperboard. All hot melts demonstrated failure at the substrate when tested on corrugated paperboard and non-glossy paperboard, but only demonstrated moderate success when applied to glossy paperboard.

\subsubsection{Use of Plasticizer}

Testing of the hot melt adhesive, being a secondary objective of this study, was relatively minimal, but showed success and promise as a hot melt adhesive composed of polylactic acid. Some of the resins, after they had been dried in the oven were relatively 
free of solvent and hard and brittle at room temp. To these samples various plasticizers were blended and their performance as a hot melt adhesive were evaluated. The plasticizers used are detailed in Section 3.3.3.1. Plasticizer content was tested ranging from 5 weight percent up to 20 weight percent by melting the polymer and mixing in plasticizer by hand using a spatula. All plasticizers in all samples were found to reduce the adhesive ability of the polymer. In addition none were found to be fully miscible with the polymer after the polymer had cooled to room temperature; phase separation was observed.

\subsubsection{Blending}

Some of the samples still retained a fair amount of their solvent even after drying and were extremely tacky, and in a near fluid, high viscosity state. These alone were unsuitable as a hot melt adhesive since they can nearly flow under the force of gravity. However, it was found that blending these with the polymers that were hard and brittle that a suitable hot melt adhesive was formed. These were generally mixed in equal parts. For example, PLA 7 was extremely viscous and tacky (molecular weight 3,400 g/mol), and was mixed with PLA 12 which dried well and as a result was hard and brittle (molecular weight 33,000 g/mol).

\subsubsection{Thermal Properties}

Differential scanning calorimetry was performed on the synthesized polymers to determine their glass transition temperatures $\left(\mathrm{T}_{\mathrm{g}}\right)$. The results of this are detailed in Table 4.1. None of the polymers exhibited a melting point, indicative of highly amorphous polymers, which simply soften over a range of temperatures. While the $\mathrm{T}_{\mathrm{g}}$ was largely 
dependent on the amount of residual solvent present in the sample, there was a correlation in molecular weight with $\mathrm{T}_{\mathrm{g}}$ as seen in Figure 4.1. This correlation, although weak, shows an $\mathrm{R}^{2}$ value of 0.77 , indicating that some type of relation is present, as expected.

Table 4.1 Summary of the glass transition temperatures $\left(T_{g}\right)$ and molecular weights for the polymers synthesized.

$\begin{array}{ccc}\text { Sample } & \left.\text { Tg } \mathbf{(}^{\circ} \mathbf{C}\right) & \text { Mn }(\mathbf{g} / \mathbf{m o l}) \\ \text { PLA 10 } & 19.87 & 47,000 \\ \text { PLA 11 } & 42.01 & 43,000 \\ \text { PLA 12 } & 36.52 & 33,000 \\ \text { PLA 9 } & 26.07 & 30,000 \\ \text { PLA 1 } & 31.05 & 21,000 \\ \text { PLA 8 } & 8.71 & 11,000 \\ \text { PLA 6 } & 5.93 & 10,000 \\ \text { PLA 7 } & 16.48 & 3,400\end{array}$

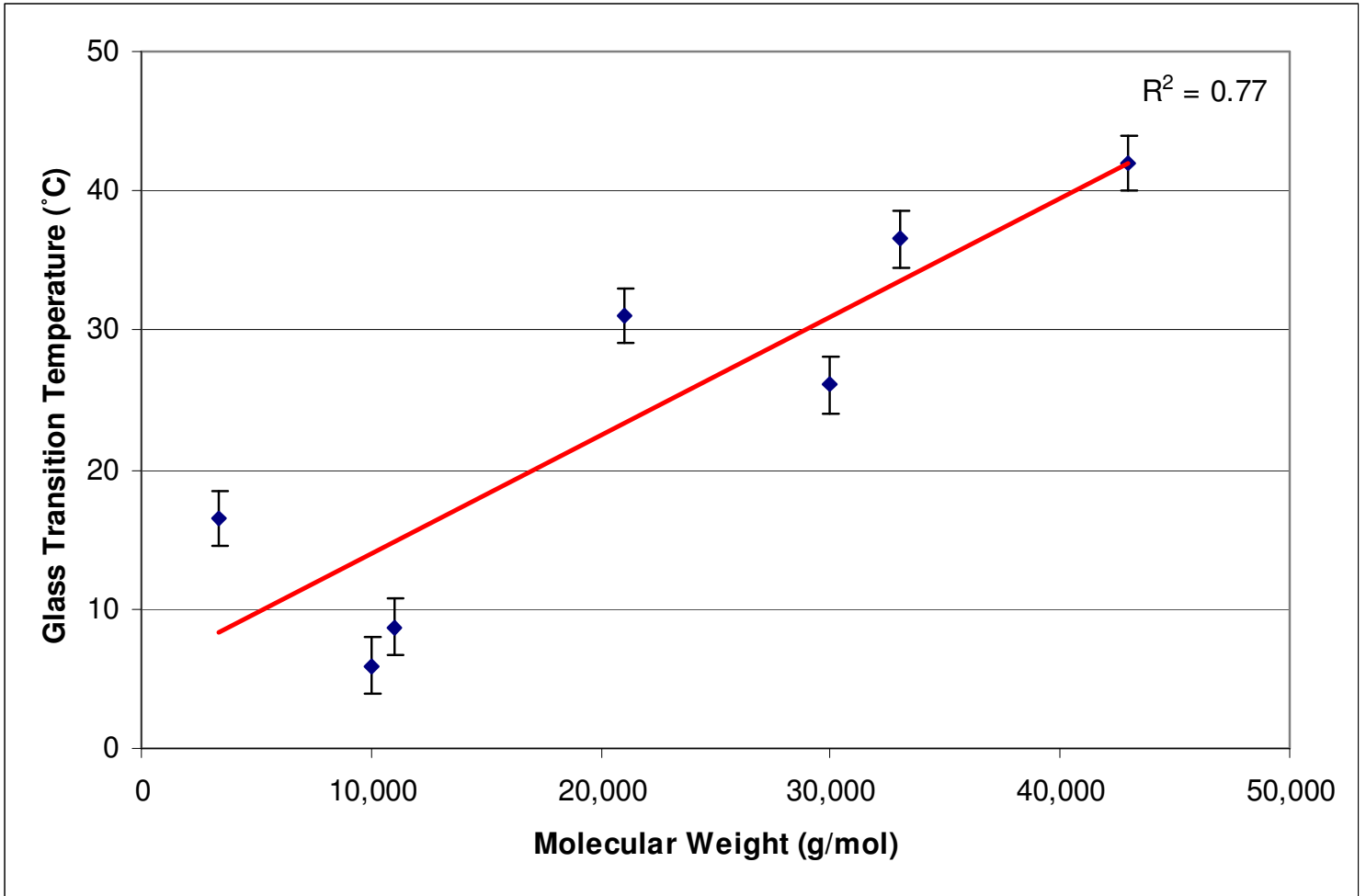

Figure 4.1 Graph of $\mathrm{T}_{\mathrm{g}}$ versus molecular weight. [An error of $\pm 2{ }^{\circ} \mathrm{C}$ is assumed due to unknown amount of residual solvent entrapped in samples.] 


\subsubsection{Thermal Stability}

Because these polymers are intended to be used as hot melt adhesives it is important to consider their thermal stability. The decomposition onset temperature is an important factor to consider for this application. In the case of the polymers prepared in this study the lowest decomposition temperature observed was $282{ }^{\circ} \mathrm{C}$, which can be seen in Table 4.2, which is far greater than the temperature for any normal hot melt. PLA also degrades fully under heat and leaves no ash. Because of this the temperature at which zero mass remains was also measured and ranged from 321 to $388{ }^{\circ} \mathrm{C}$ for the samples tested.

Table 4.2 Thermal stability of polymers synthesized for use as a hot melt adhesive.

$\begin{array}{ccc}\text { Sample } & \text { Decomposition Onset Temp }\left({ }^{\circ} \mathbf{C}\right) & \text { Temp }\left({ }^{\circ} \text { C) }\right. \\ \text { PLA 1 } & 282 & 388 \\ \text { PLA 6 } & 305 & 350 \\ \text { PLA 7 } & 293 & 354 \\ \text { PLA 8 } & 302 & 330 \\ \text { PLA 9 } & 293 & 349 \\ \text { PLA 10 } & 307 & 362 \\ \text { PLA 11 } & 303 & 361 \\ \text { PLA 12 } & 298 & 321\end{array}$

\subsubsection{Temporal Stability}

The polymers used for the hot melt adhesive showed various amounts of degradation over the duration of the study. The polymers used for the hot melt were synthesized in the winter of 2010 and were able to be tested at various times after their synthesis.

\subsubsection{Thermal Stability}

The polymers prepared in this study were synthesized in the winter and spring of 2010, which has allowed for the study of how the polymers degrade over time. Figure 4.2 is a TGA plot of sample PLA 1 in April 2010, and six months later in October 2010. 
After the PLA sample has sat in a drawer for six months it exhibits a higher temperature of decomposition; however, it also shows a higher rate of thermal degradation. The reason for this is likely that the April PLA sample has less solvent entrapped within its matrix. Although the only two solvents entrapped within the polymer are hexanes and toluene which boil at $69{ }^{\circ} \mathrm{C}$ and $111{ }^{\circ} \mathrm{C}$, respectively, much of this solvent is likely not to evaporate until the polymer is in a fully molten state. However, given a polymer that has sat for six months at a temperature near its $\mathrm{T}_{\mathrm{g}}$ with solvents that have an appreciable vapor pressure, some of that solvent may evaporate slowly over time as it migrates from the polymer matrix to the surface. This is likely the cause of the increased temperature of degradation; there is simply less entrapped solvent, which will raise the thermal properties of the material. However, it is observed that the rate of degradation is higher for the April polymer. This is likely due to a lowering of molecular weight over time, as is shown in section 4.3.6.2. A polymer that has a lower molecular weight is likely to degrade faster than a polymer of higher molecular weight. 


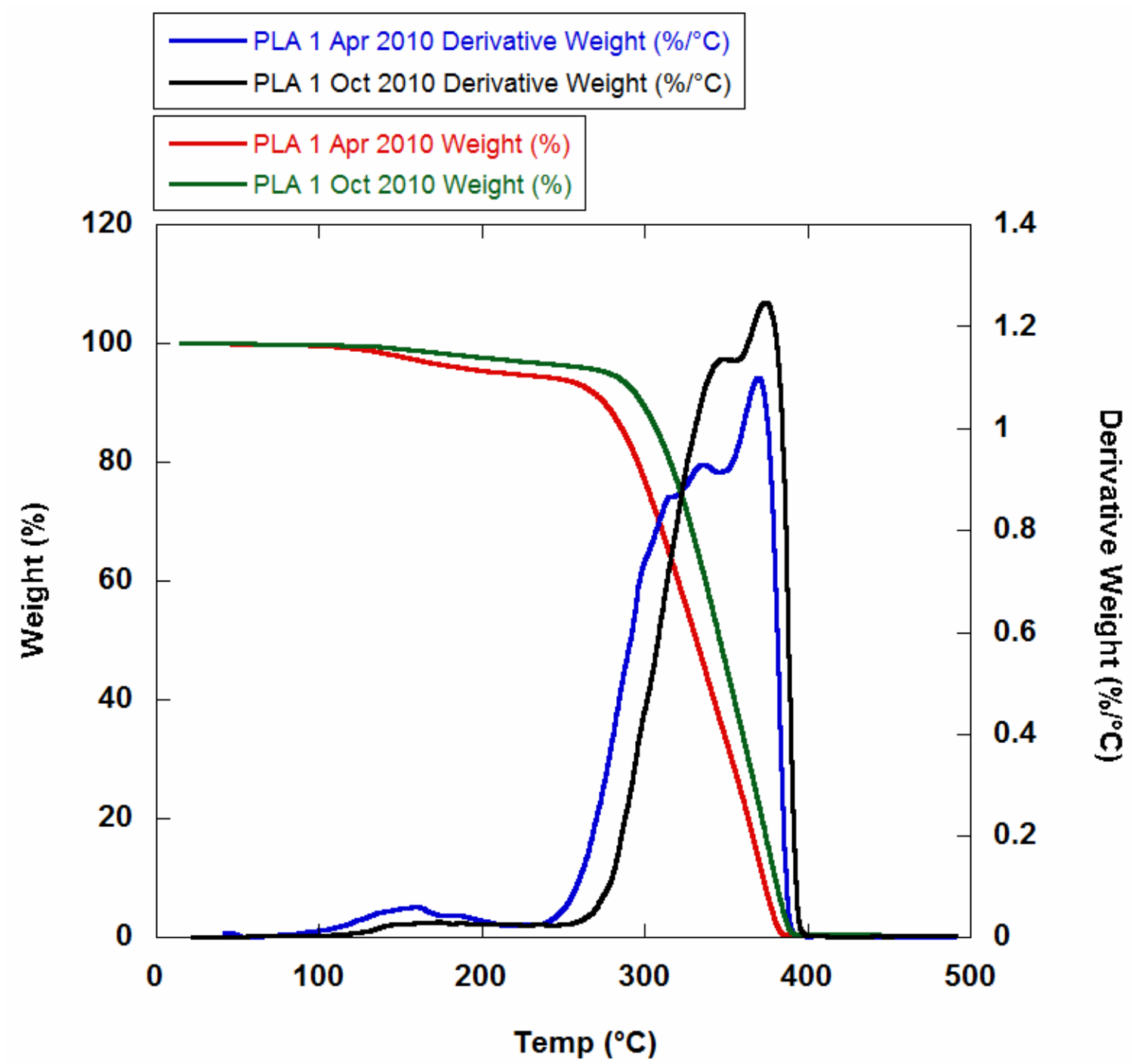

Figure 4.2 Thermal stability for PLA 1. Red - PLA 1 Apr 2010 wt \%; green - PLA 1 Oct 2010 wt \%; blue - PLA 1 Apr 2010 derivative wt \%; black - PLA 1 Oct 2010 derivative wt \%.

\subsubsection{Lowering of Molecular Weight Over Time}

Because the samples have sat for over one year since synthesis, study of how their molecular weight degrades over time is possible. Figures $4.3-4.5$ show GPC traces of PLAs 1, 11, and 12, respectively. In all plots the red trace represents the polymer soon after it was synthesized and dried in March 2010 (February 2010 for PLA 1), the blue curve represents the polymer after it has sat for six months, and the green curve 
represents the polymer after it has sat for 14 months. A summary of their molecular weights and MWDs over time is shown in Table 4.3. In all samples the molecular weight is reduced over time, showing that the polymers do degrade over time in ambient conditions. The molecular weight distributions for the polymers also increase over time, which further gives evidence to the degradation of the polymers.

Table 4.3 Summary of the molecular weights and molecular weight distributions of the polymer samples PLA 1, 11, and 12 over time.

\begin{tabular}{ccccccc} 
& \multicolumn{3}{c}{ Molecular Weight } & \multicolumn{3}{c}{ Molecular Weight Distribution } \\
Sample & Mar-10 & Oct-10 & May-11 & Mar-10 & Oct-10 & May-11 \\
PLA 1 & $21,300^{\mathrm{a}}$ & 13,600 & 13,500 & 1.27 & 1.10 & 1.28 \\
PLA 11 & 43,400 & 16,800 & 1,330 & 1.11 & 1.28 & 1.33 \\
PLA 12 & 32,600 & 26,900 & 11,900 & 1.17 & 1.06 & 1.34 \\
${ }^{a}$ Data collected Feb. 2010 & & & & &
\end{tabular}

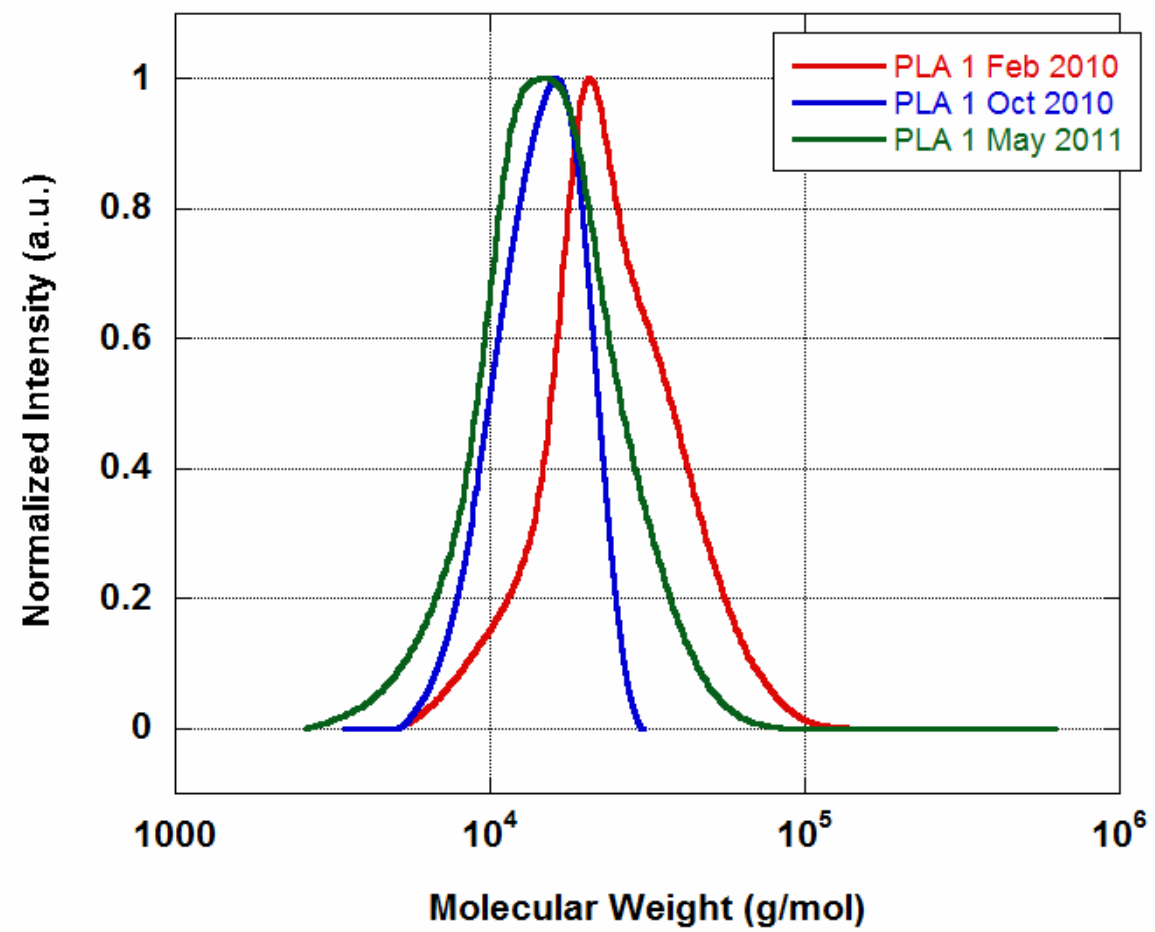

Figure 4.3 GPC analysis of PLA 1 over time. Red - Feb 2010; blue - Oct 2010; green - May 2011. 


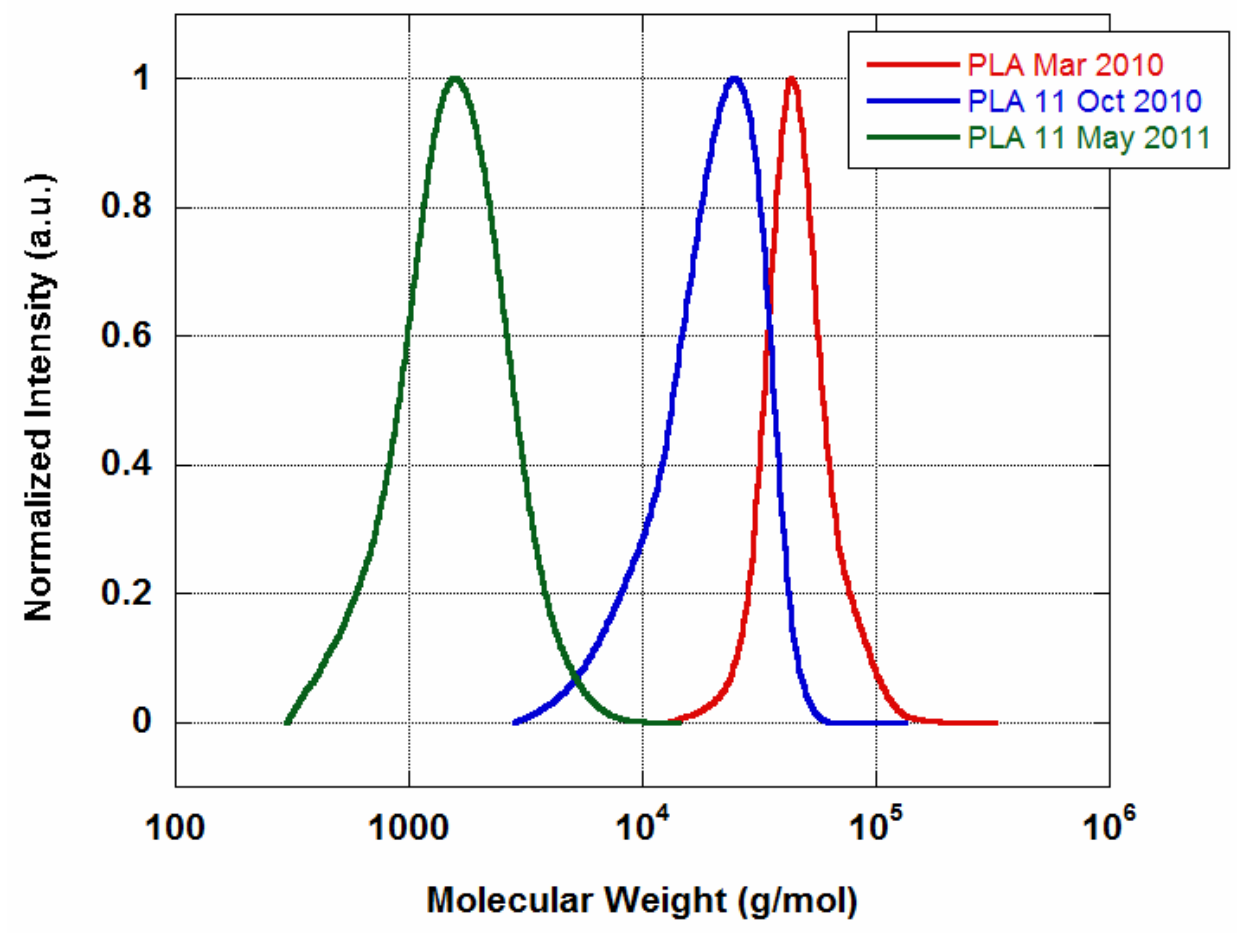

Figure 4.4 GPC analysis of PLA 11 over time. Red - Mar 2010; blue - Oct 2010; green - May 2011.

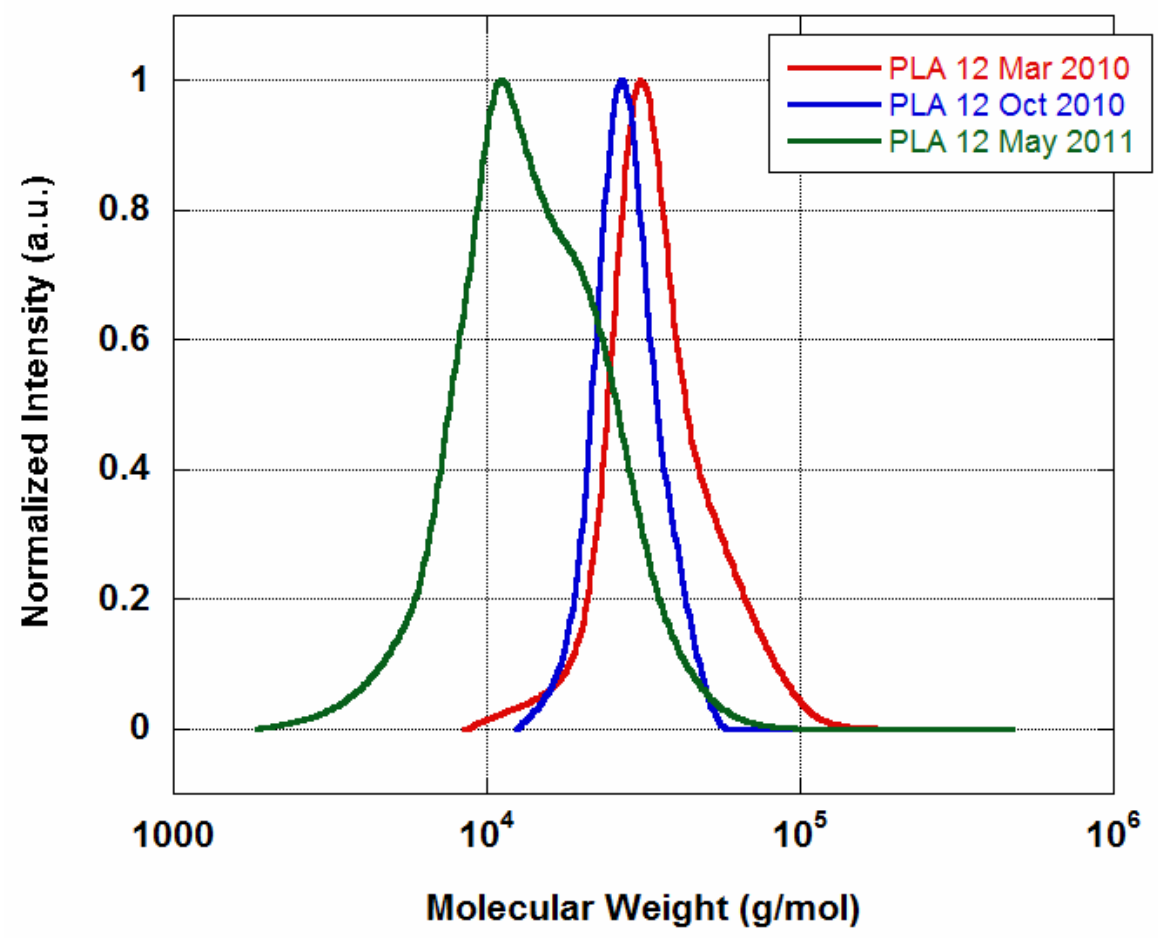

Figure 4.5 GPC analysis of PLA 12 over time. Red - Mar 2010; blue - Oct 2010; green - May 2011. 
A likely cause of the degradation is chain scission due to hydrolysis. This is not an unexpected result for PLA since it is a biodegradable polymer and designed to degrade over time. Residual solvent may also allow for a faster rate of degradation since these low molecular weight solvents act as plasticizers and increase free volume within the polymer matrix, possibly allowing for more water uptake by the polymer. In addition, it is observed that for samples PLA 11 and 12, the rate of degradation is increased from the period of Oct 2010 to May 2011, which is in agreement with the observations from the thermal studies in section 3.4.3. This is in further agreement with the fact that the degradation of PLA is an autoaccelerated process. ${ }^{47}$ The hydrolysis process of PLA can be either acid or base catalyzed, and the degradation products of PLA are acids, which leads to autoacceleration. Previous hot melts prepared from PLA/poly( $\varepsilon$-caprolactone) have also shown poor stability over time. ${ }^{48}$ This stability issue is not only true of hot melts, but with PLA films as well. ${ }^{49}$

\subsection{Conclusions}

A hot melt adhesive was developed from PLA that performed well under initial peel tests, demonstrating failure at the substrate. The polymers for this purpose were synthesized via solution polymerization, and contained small amounts of residual solvent. The polymers showed thermal and material degradation over the length of the study, although it is likely that the observed thermal degradation would not limit the usefulness of the end product. 


\section{Conclusions}

A biodegradable, waterborne coating was prepared from polylactic acid. The coating can be spray applied or laminated and shows a high level of success as a grease barrier, as it outperforms ASTM D722 for grease resistance. Various polymer architectures were employed for the development of the coating and dispersion of the polymer. A biodegradable hot melt adhesive was also developed from polylactic acid which shows potential for end-market use. The adhesive outperforms the paperboard to which it has been applied and tested on, demonstrating failure at the substrate. Further work to characterize the biodegradation and scale up for both the waterborne coating and hot melt adhesive is needed. 


\section{References}

[1] Gross, R.A, Kalra, B. "Biodegradable Polymers for the Environment." Science. 2002. 297: 803-806

[2] American Chemical Society (ACS). "Polymer Research Institute." National Historic Chemical Landmarks. 2007.

[3] Materials Science and Technology Teacher's Workshop (MAST). "History of Polymers.” 2010 University of Illinois, Department of Materials Science

[4] Vilaplana, F., Strömberg, E., Karlsson, S. "Environmental and resource aspects of sustainable biocomposites." Polymer Degradation and Stability. 2010. 95: 2147-2161

[5] Gupta, A.P., Kumar, V. "New emerging trends in synthetic biodegradable polymers Polylactide: A critique.” European Polymer Journal. 2007. 43: 4053-4074

[6] Nampoothiri, K.M., Nair, N.R., John, R.P. "An overview of the recent developments in polylactide (PLA) research." Bioresource Technology. 2010. 101: 8493-8501

[7] Witt, U., Einig, T., Yamamoto, M., Kleeberg, I., Deckwer, W.-D., Müller, R.-J. "Biodegradation of aliphatic-aromatic copolyesters: evaluation of the final biodegradability and ecotoxicological impact of degradation intermediates." Chemosphere. 2001. 44: 289-299

[8] Hermann, B.G., Blok, K., Patel, M.K. "Twisting biomaterials around your little finger: environmental impacts of bio-based wrappings." International Jounral of Life Cycle Assessments. 2010. 15: 346-358

[9] Nair, L.S., Laurencin, C.T. "Biodegradable polymers as biomaterials." Progress in Polymer Science. 2007. 32: 762-798

[10] Vink, E.T.H., Rábago, K.R., Glassner, D.A., Gruber, P.R. “Applications of life cycle assessment to NatureWorks ${ }^{\mathrm{TM}}$ polylactide (PLA) production." Polymer Degradation and Stability. 2003. 80: 403-419

[11] Tullo, A. "Cargill Buying Dow's Stake in Partnership." Chemical and Engineering News. 2005, 83: 11

[12] Ono, H., Phala, H. "Process for the production of lactide." European Patent. 1989. Application number: EP19890303989

[13] Korean Research Institute of Chemical Technology (KRICT). "Production of Lactide as a Monomer of PLA (Polylactide).” 2010. rgn.krict.re.kr. Accessed: 3 June 2011 
[14] Jung, Y.K., Lee, S.Y. "Efficient production of polylactic acid and its copolymers by metabolically engineered Escherichia coli." Journal of Biotechnology. 2011. 151: 94-101

[15] Jones, M.D., Davidson, M.G., Kociok-Kohn, G. "New titanium and zirconium initiators for the production of polylactide." Polyhedron. 2010. 29: 697-700

[16] Dechy-Cabaret, O., Matin-Vaca, B., Bourissou, D. "Controlled Ring-Opening Polymerization of Lactide and Glycolide." Chemical Review. 2004. 104: 6147-6176

[17] Ryner, M., Stridsberg, K., Albertson, A.C., von Schenck, H., Svensson, M. "Mechanism of Ring-Opening Polymerization of 1,5-Dioxepan-2-one and L-Lactide with Stannous 2-Ethylhexanoate. A Theoretical Study." Macromolecules. 2001. 34: 3877-3881.

[18] Puppi, D., Chiellini, F., Piras, A.M., Chiellini, E. "Polymeric materials for bone and cartilage repair." Progress in Polymer Science. 2010. 35: 403-440

[19] Gollwitzer, H., Ibrahim, K., Meyer, H., Mittelmeier, W., Busch, R., Stemberger, A. "Antibacterial poly(D,L-lactic acid) coating of medical implants using a biodegradable drug delivery technology." Journal of Antimicrobial Chemotherapy. 2003. 51: $585-591$

[20] Sharkawi, T., Leyni-Barbaz, D., Chikh, N., McMullen, J.N. "Evaluation of the In Vitro Drug Release from Resorbable Biocompatible Coatings for Vascular Stents." Journal of Bioactive and Compatible Polymers. 2005. 20: 153-168

[21] Aarnio, T., Hämäläinen, A. "Challenges in packaging waste management in the fast food industry." Resources Conservation \& Recycling. 2008. 52: 612-621

[22] Dai, J.S., Caldwell, D.G. "Origami-based robotic paper-and-board packaging for food industry." Trends in Food Science \& Technology. 2010. 21: 153-157

[23] Davis, G., Song, J.H. "Biodegradable packaging based on raw materials from crops and their impact on waste management." Industrial Crops and Products. 2006. 23: 147-161

[24] Appendini, P., Hotchkiss, J.H. "Review of antimicrobial food packaging." Innovative Food Science \& Emerging Technologies. 2002. 3: 113-126

[25] Jin, T., Liu, L., Zhnag, H., Hicks, K. “Antimicrobial activity of nisin incorporated in pectin and polylactic acid composite films against Listeria monocytogenes." International Journal of Food Science and Technology. 2009. 44: 322-329 
[26] Mascheroni, E., Guillard, V., Nalin, F., Mora, L., Piergiovanni, L. "Diffusivity of propolis compounds in Polylactic acid polymer for the development of antimicrobial packaging films." Journal of Food Engineering. 2010. 98: 294-301

[27] Hakkarainen, M. "Aliphatic Polyesters: Abiotic and Biotic Degradation and Degradation Products." Advances in Polymer Science. 2002. 157: 113-138

[28] Arora, A., Padua, G.W. "Review: Nanocomposites in Food Packaging." Journal of Food Science. 2010. 75: 43-49

[29] Bordes, P., Pollet, E., Avérous, L. "Nano-biocomposites: Biodegradable polyester/nanoclay systems." Progress in Polymer Science. 2009. 34: 125-155

[30] Dahmane, H. "Development of environmentally friendly warm-melt adhesives for the packaging industry." International Journal of Adhesion and Adhesives. 1996. 16: 43-45

[31] Chen, X., Zhong, H., Jia, L., Ning, J., Tang, R., Qiao, J., Zhang, Z. "Polyamides derived from piperazine and used for hot-melt adhesives: synthesis and properties." International Journal of Adhesion \& Adhesives. 2002. 22: 75-79

[32] Park, Y-J., Kim, H-J. "Hot-melt adhesive properties of EVA/aromatic hydrocarbon rein blend." International Journal of Adhesion \& Adhesives. 2003. 23: 383-392

[33] Viljanmaa, M., Södergård, A., Törmälä, P. “Adhesion properties of lactic acid based hot melt adhesives and their storage stability in different packaging applications." International Journal of Adhesion \& Adhesives. 2002. 22: 447-457

[34] Choi, W.Y., Lee. C.M., Park, H.J. "Development of biodegradable hot-melt adhesive based on poly- $\varepsilon$-caprolactone and soy protein isolate for food packaging system."

LWT. 2006. 39: 591-597

[35] Ham-Pichavant, F., Sèbe, G., Pardon, P., Coma, V. "Fat resistance properties of chitosan-based paper packaging for food applications." Carbohydrate Polymers. 2005. 61: 259-265

[36] Kjellgren, H., Gällstedt, M., Engström, G., Järnström, L. "Barrier and surface properties of chitosan-coated greaseproof paper." Carbohydrate Polymers. 2006. 65: 453-460

[37] Tulig, J.T., Tirrell, M. "Molecular theory of the Trommsdorff effect." Macromolecules. 1981. 14: 1501-1511 
[38] Liu, J., Lou, L., Yu., W., Liao, R., Li, R., Zhou, C. "Long chain branching polylactide: Structures and properties." Polymer. 2010. 51: 5186-5197

[39] Pitet, L.M., Hait, S.B., Lanyk, T.J., Knauss, D.M. "Linear and Branched Architectures from the Polymerization of Lactide with Glycidol." Macromolecules. 2007. 40: $2327-2334$

[40] Pellegrino, T., Manna, L., Kudera, S., Liedl, T., Koktysh, D., Rogach, A.L., Keller, S., Rädler, J., Natile, G., Parak, W.J. "Hydrophobic Nanocrystals Coated with an Amphiphlic Polymer Shell: A General Route to Water Soluble Nanocrystals." Nano Letters. 2004. 4: 703-707

[41] Saito, Shuji. "Solubilization properties of polymer-surfactant complexes." Journal of Colloid and Interface Science. 1967. 2: 227-234

[42] Choi, Y.K., Bae, Y.H, Kim, S.W. "Star-Shaped Poly(ether-ester) Block Copolymers: Synthesis, Characterization, and Their Physical Properties." Macromolecules. 1998. 31: $8766-8774$

[43] Quintanar-Guerrero, D., Fessi, H., Allemann, E., Doelker, E. "Influence of stabilizing agents and preparative variables on the formation of poly(D,L-lactic acid) nanoparticles by an emulsification-diffusion technique." International Journal of Pharmaceutics. 1996. 143: 133-141.

[44] Environmental Protection Agency (EPA). "Air Quality: Revision to Definition of Volatile Organic Compounds - Exclusion of Acetone.” 40 CFR Part 511995.

[45] Kurganov, B.I., Topchieva, I.N., Efremova, N.V. "Protein Conjugates with Watersoluble Poly(alkylene oxide)s Entrapped in Hydrated Reversed Micelles." Bioconjugate Chemistry. 1997. 8: 637-642

[46] Zhang, Y., Jiang, M., Zhao, J., Zhou, J., Chen, D. "Hollow Spheres from Shell Cross-Linked, Noncovalently Connected Micelles of Carboxy-terminated Polybutadiene and Poly(vinyl alcohol) in Water." Macromolecules. 2004. 37: 15371543

[47] Yanfeng, Luo., Wang Yuanliang, Niu Xufeng, Fu Chunhua, Wang Sujun. "Synthesis, characterization, and biodegradation of butanediamine-grafted poly(DL-lactic acid)." European Polymer Journal. 2007. 43: 3856-3864

[48] Viljanmaa, M., Södergård, A., Törmälä, P. "Lactic acid based polymers as hot melt adhesives for packaging applications." International Journal of Adhesion \& Adhesives. 2002. 22: 219-226 
[49] Holm, V.K., Ndoni, S., Risbo, J. "The Stability of Poly(lactic acid) Packaging Films as Influenced by Humidity and Temperature." Journal of Food Science. 2006. 71: 40-44 